\title{
1 Dissimilar friction stir welds in AA2219-AA5083 aluminium alloys: Effect of process 2 parameters on material inter-mixing, defect formation, and mechanical properties.
}

3 P.Mastanaiah ${ }^{1}$, Abhay Sharma ${ }^{2 \#}$, G.Madhusudhan Reddy ${ }^{3 \# \# .}$

$5 \quad{ }^{1}$ Defence Research and Development Laboratory,

6 Kanchanbagh, Hyderabad,

7 Telangana, India -500058.

8 E-mail address:mastanaiahp@gmail.com

${ }^{2}$ Indian Institute of Technology Hyderabad, ODF Estate, Yeddumailaram,

12 Telangana, India-502205.

13 Tel.: +91 4023016091.

14 E-mail address: abhay@iith.ac.in

${ }^{3}$ Defence Metallurgical Research Laboratory,

17 Kanchanbagh, Hyderabad,

18 Telangana, India -500058.

19 Tel.:+914024345048.

20 E-mail address:gmreddydmrl@yahoo.co.in

\section{Abstract}

Dissimilar friction stir welds of aluminium alloys AA 5083 and AA2219 were investigated in a view to get defect free welds by varying process parameters. An attempt has been made to develop a mathematical model to predict sound welds. Design of experiments with three parameters and five levels were used to optimize the effectiveness of process parameters. Analysis of variance and response surface methodology were used to determine the significance and optimal level for each parameter to minimize $\%$ area of volumetric defect. The experimental and predicted values of $\%$ area of defect were in good agreement. The effects of process parameters and tool-offset on the extent of intermixing of materials and to minimize $\%$ area of volumetric defects are analyzed in detail by employing different methods such as macrostructural analysis and electron probe micro analysis. The defect free dissimilar weldments were characterized for transverse tensile properties. The observed tensile strength values were correlated with reference to the extent of intermixing of materials in the stir/nugget zone. Established mathematical models which have depicted a good prediction of relationship between the investigated FSW process parameters and the \% area of defect of the welds. It is understood

"Co-corresponding Author

\#\#Corresponding Author 
that the mixing pattern in nugget zone and further joint strength are primarily affected by the tool offset and welding parameters.

Key words: Dissimilar friction stir welding, AA2219 alloy, AA5083 alloy, defect formation, mechanical properties

\section{1. Introduction}

The welding of aluminium alloys has always posed serious challenges to designers and technologists. Several difficulties such as porosity, hot cracking and distortion are associated with the fusion welding of aluminium alloys [1]. These problems can be controlled to a large extent by employing solid state welding processes. Friction stir welding (FSW) process is an emerging solid state welding process in which the material is being welded does not melt and recast [2]. The advantages of FSW over conventional fusion welding have been reported by many researchers $[2,3]$ particularly for the industries those rely heavily on joining of aluminium alloys [4].

Numerous researchers across the world have extensively exploited this process during the last two decades and the major part of research is on joining of similar and dissimilar aluminum alloys. Dissimilar metal combinations are the need of the day due to the rising exploration of newer materials and new design requirements. The joining of dissimilar metals is generally more challenging and complex than that of similar metals because of difference in physical, mechanical and metallurgical properties of the parent metal to be joined. Interest has also generated for FSW of dissimilar metals and alloys particularly systems which are difficult or impossible to weld by conventional fusion welding.

The problem associated with FSW of dissimilar alloys is that each materials responds in different manner at higher temperatures with respect to the deformation mechanism. So it would be difficult to arrive at common welding parameters which suits to both the materials. Jamshidi et al. [5] investigated the thermo-mechanical and microstructural evolution in similar and dissimilar friction stir welding of AA 6061 and AA 5086-O. It was observed that the hardness in AA 5086 side mainly depends on the recrystallization and generation of fine grains in weld nugget while hardness in AA6061 side varies with size, volume fraction and distribution of the precipitates in the weld zone and heat affected zone as well as ageing period after welding.

Ghosh et al. [6] studied the optimization of friction welding parameters for dissimilar aluminium alloys ( A356 and 6061) under tool rotational speed of 1000-1400 rpm and traversing speed of $80-240 \mathrm{~mm} / \mathrm{min}$. Processing at low tool rotation and traversing speed results in fine grain size, reduce residual thermal stress, decrease extent of recovery-recrystalization, promote finer distribution of Si rich particles and improve consolidation of transport material at the back of the tool to eliminate discontinuities within weld nugget. All these factors have synergistic effect in improving the mechanical properties of dissimilar joints. . 
Mechanical properties of FSW welded similar and dissimilar aluminum alloys showed that position of the tool with respect to original joint interface affects strength and ductility of the joints. The improper position of the tool can cause the FSW defect known as joint line remnant. Normally linear welds are made for research purpose, but actual applications may demand contour welds. In contour welds the interface position with respect to tool pin may change slightly. The effect of this deviation and importantly, its allowable range is not known. A prior understanding on the maximum allowable tool axis offset is highly essential in these industrial applications. The optimum strength and ductility of the weld can be obtained only if the tool offset distance is optimized. Kumar and Satish [7] reported that there exists a tolerance limit for the deviation of the tool from the joint interface without deteriorating the joint efficiency of AA7020-T6 friction stir welds.

The formation of defect free weld is affected by material flow behaviour under the action of rotating non consumable tool. However material flow is predominately influenced by welding condition especially the tool rotational speed, traverse speed and relative position of material in case of dissimilar joining; because these conditions are key factors for heat input and the material flow and intermixing. The flow of the material is not fully understood despite several investigations and models have been reported. Several studies have been carried out on effect of process parameters and tool geometry on material flow during welding of similar weldments $[8$, $9,10]$. However variations in the material flow as a function of variations in the processing parameters and material properties are not well established. One can reasonably estimate that a process having high strain rate would result in a very effective mixing of the alloys, but in reality this is the seldom the case. The placement of materials among the dissimilar alloys on advancing side or retreating side is also an important aspect affecting the material flow pattern and the resulting weld quality, mechanical properties [11].The material flow and microstructural evolution during FSW of dissimilar alloys are relatively complex and the understanding of the same requires extensive experimentation [11]. These differences in physical and thermal properties contribute to variations in the heat generation and material flow during FSW. The role of tool-offset on flow behaviour has not been explicitly addressed in the past from the perspective of comparable thermal softening of metals being joined.

Offsetting of tool is seldom employed in case of joining of dissimilar materials which are entirely different in physical and metallurgical characteristics. Genevois et al.[12]studied the interfacial reactions in FSW joints of aluminium to copper, in which the tool was completely parked in aluminium and Xue et al.[13]investigated on effect of friction stir welding parameters on microstructure and mechanical properties of dissimilar Al-Cu joints. Generally tool is almost completely positioned in softer aluminium alloy to join to harder steels or aluminium to titanium alloys through FSW. Cavaliere et al. [14] joined AA2024 to AA7075 alloys and noticed that offsetting the tool axis towards AA2024 (softer of two) which is placed in advancing side considerably improves the tensile and fatigue properties of weld joint. 
Investigation by Amancio-Filho et al. [15] on the microstructures of dissimilar friction stir welds of AA 2014 and AA 6056, produced by placing stronger AA2014 on advancing side, showed that only an intimate physical contact between materials existed. Park et al. [16] studied the locations of two dissimilar alloys that exerted a significant effect on material mixing between AA5082 and AA 6061 in the weld nugget. By placing the stronger material on the advancing side the proper mixing was observed than that of when alloy 5082 was placed on the advancing side. In contrast, a thinner weld nugget and inadequate mixing occurred with 6061 on the advancing side.

Dilip et al. [17] reported improperly mixed friction stir welds of AA2219 and AA5083, in which the harder AA2219 alloy was positioned on advancing side. The previous efforts in material flow during FSW of dissimilar aluminum alloys are qualitative in nature. No such investigation is revealed where quantitative assessment of material flow in dissimilar alloy FSW, i.e., amount dilution of one alloy into another alloy in the intermixed nugget zone and its impact on joint strength is attempted. Moreover, relation between process parameters, namely, traverse speed, tool rotation, and tool offset and material flow needs to be better understood.

In order to study the effect of FSW process parameters, the traditional experimental technique is varying one parameter at a time while keeping other constant. This traditional step by step approach for optimization purpose involves a large number of independent runs and does not take into account the possible interactions between factors. To avoid these disadvantages, the use of design of experiment concept is the most efficient means to reach conclusions with a minimum number of experiments. To obtain the high strength and defect free joints, it is necessarily to have a complete control over the relevant process parameters. Therefore, it is important to select and control the welding process parameters for obtaining the good quality joints.

The aluminum alloy AA 2219 and AA 5083 are used in fabrication of aircraft structures and other structural applications. Dissimilar joints between AA 2219 and AA 5083 would be required in the future for aerospace and transportation applications to increase the possibilities for flexible design and get the benefits from each of material in a functional way. The aim of this study was to investigate the extent of the welding window, i.e. the range of friction stir welding process parameters within which good quality welds could be produced between dissimilar alloys AA 5083 and AA 2219. The present investigation seek to develop insight into the effect of process parameters on, material inter-mixing and defect formation and thereby relating them to the mechanical properties.

\section{Experimental Work}

The parent materials under the present investigation were AA2219-T6 Al-Cu alloy and AA5083 $\mathrm{Al}-\mathrm{Mg}$ alloy. The analyzed chemical compositions and mechanical properties are furnished in Table 1.The coupon width was maintained along the rolling direction. Friction stir welding of 
$75 \mathrm{~mm}$ width $\mathrm{x} 125 \mathrm{~mm}$ length $\mathrm{x} 5 \mathrm{~mm}$ thickness plates was carried out in square butt joint configuration by positioning the AA5083 alloy on advancing side, on a position controlled FSW machine. A typical good quality dissimilar weld joint and its X-ray radiograph are shown in Fig. 1.

\section{Table 1. Chemical composition $(\% \mathrm{Wt})$ and mechanical properties of parent materials}

\begin{tabular}{|c|c|c|c|c|c|c|c|c|c|c|c|c|c|}
\hline \multirow[b]{2}{*}{ Parent Material } & \multicolumn{9}{|c|}{ Chemical composition } & \multicolumn{3}{|c|}{ Tensile properties } & \multirow[b]{2}{*}{$\begin{array}{l}\text { Micro } \\
\text { hardness (VHN) }\end{array}$} \\
\hline & $\% \mathrm{Cu}$ & $\% \mathrm{Si}$ & $\% \mathrm{Mn}$ & $\% \mathrm{Mg}$ & $\% \mathrm{~V}$ & $\% \mathrm{Zn}$ & $|\% \mathrm{Ti}|$ & $\% \mathrm{Cr}$ & $\% \mathrm{Fe}$ & \begin{tabular}{|l|}
$\mathrm{UTS}$ \\
$(\mathrm{MPa})$
\end{tabular} & $\begin{array}{l}0.2 \% \mathrm{YS} \\
(\mathrm{MPa})\end{array}$ & $\%$ El. & \\
\hline AA2219-T6 & 5.83 & 0.03 & 0.3 & --- & 0.08 & 0.054 & 0.04 & -- & 0.1 & 443 & 338 & 10 & 139 \\
\hline AA5083-H116 & -- & 0.13 & 0.66 & 4.2 & --- & 0.01 & 0.01 & 0.01 & 0.3 & 306 & 146 & 20 & 80 \\
\hline
\end{tabular}
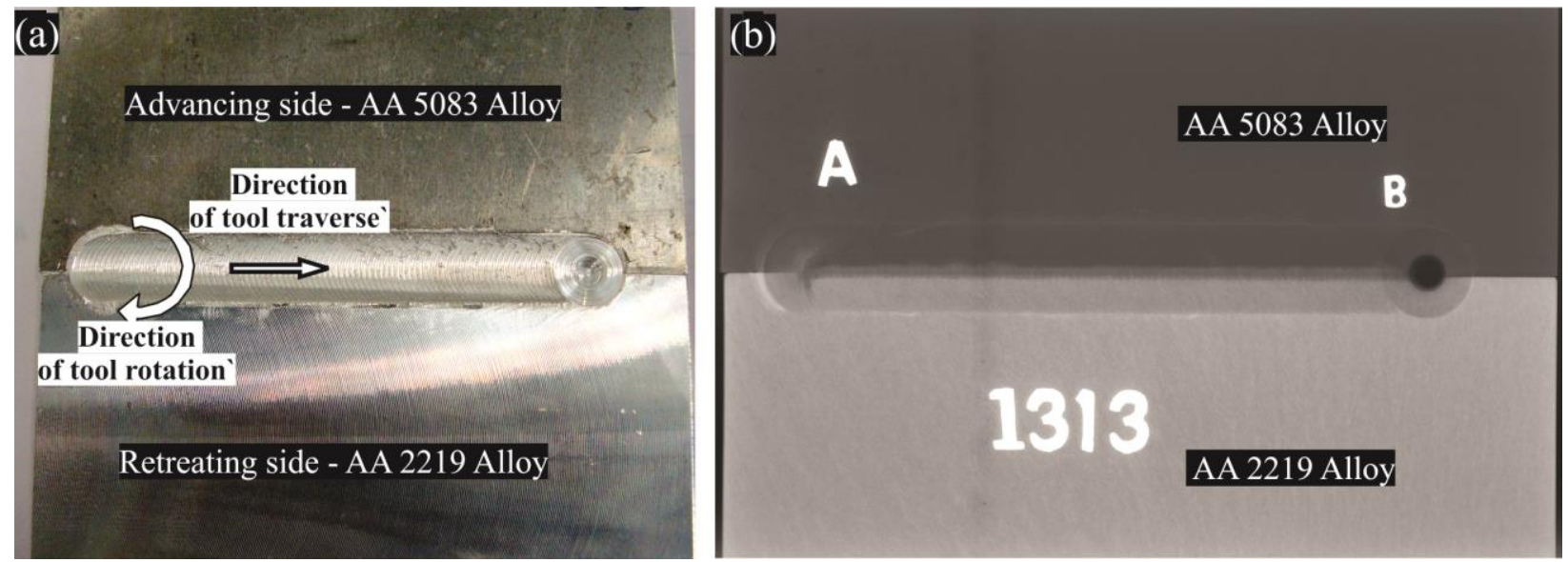

Fig. 1.(a) Defect free dissimilar friction stir weld joint and (b) X-ray radiograph

\section{( $\mathrm{N}=400 \mathrm{rpm}, \mathrm{S}=570 \mathrm{~mm} / \mathrm{min}, \mathrm{O}=1 \mathrm{~mm}$ towards AA5083 alloy side)}

The flow stress of AA5083 alloy is higher than that of AA2219 alloy [18, 19], in view of this AA5083 alloy was placed on advancing side. Consequently the material on advancing side was envisaged to experience greater shearing and heating than that of retreating side. The employed tool was made of $\mathrm{H} 13$ grade tool steel with a $15 \mathrm{~mm}$ diameter shoulder and a frustum shaped threaded pin of $6 \mathrm{~mm}$ top diameter and $4 \mathrm{~mm}$ bottom diameter. A constant tool tilt of $2^{0}$ was used in all the experiments. The predominant factors such as tool rotational speed, welding (traverse) speed, tool off set from joint centre line were varied during experimentation, which were expected to have significant influence on quality of joints. Numerous trial experiments were conducted to determine the working range of above process parameters. Feasible limits of the parameters were chosen in such a way that the friction stir welded joints should be free from any external visible defects. The influencing process parameters and their working range are shown in Table 2. Each process parameter was divided into five levels. The negative sign for the tool offset indicates shifting of tool towards AA2219 side while positive sign indicates shifting of tool axis towards AA5083 alloy side. 
173 Table 2. Welding process parameters and their levels used in the experimentation

\begin{tabular}{|l|l|l|l|l|l|l|l|}
\hline S.No. & Process Parameter & Symbol & \multicolumn{5}{|c|}{ Levels } \\
\hline 1 & Tool rotation speed (rpm) & N & 400 & 800 & 1200 & 1600 & 2000 \\
\hline 2 & Tool traverse speed $(\mathrm{mm} / \mathrm{min})$ & S & 30 & 210 & 390 & 570 & 750 \\
\hline 3 & Tool offset from joint line $(\mathrm{mm})$ & O & -2 & -1 & 0 & +1 & +2 \\
\hline
\end{tabular}

174 The experiments were conducted on a position controlled friction stir welding machine using

175 L25 orthogonal array that offers well-distributed experiments over a wide range of experimental 176 conditions as shown in Table 3 . The weld joints were initially visually inspected and further

177 subjected to X-ray radiography to inspect for the presence of various internal and surface defects

178 respectively. The weld macrostructures of transverse section were examined under optical

179 metallurgical microscope, after standard metallographic sample preparation using modified

180 Keller's reagent.

181 Table 3. L25 orthogonal array along with its experimental results and predicted values 182 from the regression model

\begin{tabular}{|l|l|l|l|l|l|l|}
\hline \multirow{2}{*}{$\begin{array}{l}\text { Expt. } \\
\text { No. }\end{array}$} & \multicolumn{2}{|l|}{ FSW Parameters } & \multicolumn{2}{l|}{ \% Defect in Nugget Zone } & $\begin{array}{l}\text { Error }= \\
\text { (Experimental - } \\
\text { Predicted) in } \%\end{array}$ \\
\hline 1 & $\mathrm{~N}$ & $\mathrm{~S}$ & $\mathrm{O}$ & Predicted & Experimental \\
\hline 2 & 400 & 30 & -2 & 2.4677 & 0 & 2.4677 \\
\hline 3 & 400 & 210 & -1 & 0.9493 & 0 & 0.9493 \\
\hline 4 & 400 & 390 & 0 & 0.9293 & 0 & 0.9293 \\
\hline 5 & 400 & 570 & +1 & 2.4077 & 0 & 2.4077 \\
\hline 6 & 400 & 750 & +2 & 5.3845 & 2 & 3.3845 \\
\hline 7 & 800 & 30 & -1 & 1.1017 & 1 & 0.1017 \\
\hline 8 & 800 & 210 & 0 & 1.2153 & 0 & 1.2153 \\
\hline 9 & 800 & 390 & +1 & 2.8273 & 0 & 2.8273 \\
\hline 10 & 800 & 570 & +2 & 5.9377 & 0 & 5.9377 \\
\hline 11 & 800 & 750 & -2 & 5.0965 & 0 & 5.0965 \\
\hline 12 & 1200 & 30 & 0 & 1.1677 & 0 & 1.1677 \\
\hline 13 & 1200 & 210 & +1 & 2.9133 & 1.2 & 2.9133 \\
\hline 14 & 1200 & 390 & +2 & 6.1573 & 3 & 3.1573 \\
\hline 15 & 1200 & 570 & -2 & 9.9297 & 5 & 4.9297 \\
\hline 16 & 1200 & 750 & -1 & 9.6505 & 11 & -1.3495 \\
\hline 17 & 1600 & 30 & +1 & 2.6657 & 1 & 1.6657 \\
\hline 18 & 1600 & 210 & +2 & 6.0433 & 10 & -3.9567 \\
\hline 19 & 1600 & 390 & -2 & 14.4293 & 14 & 0.4293 \\
\hline 20 & 1600 & 570 & -1 & 14.2837 & 8 & 6.2837 \\
\hline 21 & 1600 & 750 & 0 & 15.6365 & 6 & 9.6365 \\
\hline 22 & 2000 & 30 & +2 & 5.5957 & 0 & 5.5957 \\
\hline 23 & 2000 & 210 & -2 & 18.5953 & 17 & 1.5953 \\
\hline 24 & 2000 & 390 & -1 & 18.5833 & 13 & 5.5833 \\
\hline 25 & 2000 & 570 & 0 & 20.0697 & 18 & 2.0697 \\
\hline & 2000 & 750 & +1 & 23.0545 & 20 & 3.0545 \\
\hline
\end{tabular}


The weld macrostructures were analyzed to measure the proportions of dissimilar materials in intermixed nugget zone, i.e., mechanical mixing of one material into another material in nugget. The weld macrostructures were also analyzed for different defects like tunnel, voids and material depletion in the form of grooves. The area proportion of such defects in the weld nugget was expressed as percentage defect $(\% \mathrm{D})$. All the experiments were repeated three times and averages of the three were used in analysis. The experimental observations on $\%$ defect in the nugget zone are given in Table 3. A mathematical model was developed using regression analysis for prediction of $\% \mathrm{D}$ area in nugget zone as a function of welding parameters such as tool rotation speed $(\mathrm{N}, \mathrm{rpm})$, tool traverse speed $(\mathrm{S}, \mathrm{mm} / \mathrm{min})$ and tool offset $(\mathrm{O}, \mathrm{mm})$ from joint centre line.

The microhardness was measured using Vickers microhardness tester at $100 \mathrm{gf}$ load. The micro hardness indentations were spaced with $0.25 \mathrm{~mm}$ intervals covering various zones of weldments and base materials across the mid thickness of the transverse weld cross section. The tensile test specimens were extracted along the transverse direction to the weld joint and the specimen geometry confirming to standard ASTM E8. The room temperature tensile properties of three specimens for each experiment were evaluated in as-welded condition on a universal tensile testing machine of INSTRON make at a crosshead speed of $1 \mathrm{~mm} / \mathrm{min}$. Face bend testing of two specimens was carried out as per standard ASTM E190.

\section{Development of regression model}

\subsection{Regression model}

Statistical design of experiment approach [20] is used to minimize the number of trials that give optimum value of the response. In addition it enables development of a regression model that establishes relationship between the process parameters and response. This relationship can be used to predict the response when the process parameters are varied within the sleeted ranges. These regression models geometrically represents surface, when plotted as response verses any two process parameters. Such plots make it possible to visualize the relation between the response and process parameters.

The response parameter representing the percentage defect $(\% \mathrm{D})$ in the nugget zone of the dissimilar FS weld joint is a function of tool rotation speed $(\mathrm{N})$, tool traverse speed $(\mathrm{S})$ and tool offset (O) from the centre line of joint. The \% defect can be expressed as :

$\% D=f(N, S, O)$

The second order polynomial regression equation for the response parameter ' $Y$ ' for ' $n$ ' number of factors may be expressed as:

$$
\mathrm{Y}=\mathrm{b}_{0}+\sum b_{i} X_{i}+\sum b_{i i} X_{i}^{2}+\sum b_{i j} X_{i} X_{j}
$$

Where, $b_{0}$ is the average of responses, $b_{i}$ and $b_{i i}$ are the coefficients that depend on the main effects (linear and quadratic) whereas $b_{\mathrm{ij}}$ represents the interaction effects of the welding 
parameters. The polynomial for the percentage of defect dependent on three input parameters may be expressed as

$\% D=b_{0}+b_{1}(N)+b_{2}(S)+b_{3}(O)+b_{11}\left(N^{2}\right)+b_{22}\left(S^{2}\right)+b_{33}\left(O^{2}\right)+b_{12}(N S)+b_{23}(S O)+$ $b_{31}(O N)$

The coefficients are calculated based on the under mentioned expressions:

$b_{0}=1.428 \times 10^{-1} \Sigma(Y)-3.571 \times 10^{-2} \Sigma \Sigma\left(X_{i i} Y\right)$

$b_{i}=4.166 \times 10^{-2} \Sigma\left(X_{i} Y\right)$

$b_{i i}=3.125 \times 10^{-2} \Sigma\left(X_{i i} Y\right)-3.72 \times 10^{-3} \Sigma \Sigma\left(X_{i i} Y\right)-3.571 \times 10^{-2} \Sigma(Y)$

$b_{i j}=6.25 \times 10^{-2} \Sigma\left(X_{i j} Y\right)$

The values of the regression coefficients in the polynomial (6) are calculated using the statistical software MINITAB version 17. The deduced second order polynomial regression equation after incorporating all the values of the regression coefficients is as follows:

$$
\begin{aligned}
& \% D=6.46-1.181 \times 10^{-2}(N)-1.25 \times 10^{-2}(S)+2.23(O)+6 \times 10^{-6}\left(N^{2}\right)-3 \times \\
& 10^{-6}\left(S^{2}\right)+6.52\left(O^{2}\right)+1.7 \times 10^{-6} b_{12}(N S)-2.24 \times 10^{-3}(O N)
\end{aligned}
$$

The percentage of defect in the nugget zone predicted from the regression model and the experimental values for 25 trials are presented in Table 3. It is clearly revealed from this table that the percentage error between the predicted and experimental values is less than $10 \%$.

\subsection{Verifying the adequacy of the model}

The statistical summary of the regression model is mentioned in the Table 4.The value of ' $\mathrm{R}$-sq' represents the extent of closeness between the predicted values and the experimental results. For a given model, higher the values of ' $\mathrm{R}$-sq' and lower values of standard error indicate that the model is adequate. The adequacy of the regression model is judged by the analysis of variance (ANOVA), whose results are shown in Table 5. It is observed that the calculated F- ratio is higher than the tabulated F-ratio at confidence level more than the $95 \%$. So, the developed model is considered to be adequate and predicts the response without appreciable error. Further, the model is verified against the plot between predicted values and the experimental results which is shown in Fig. 2. The slope of the plot is very close to 1, thus indicating that the model fits very closely with the developed regression model. 


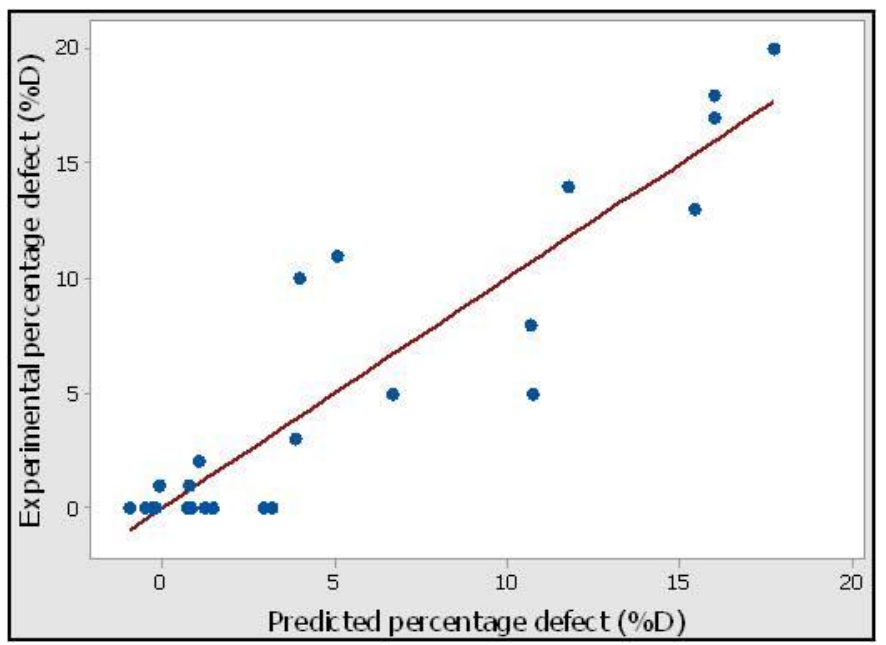

250

Fig. 2. The plot between the experimental and prediced values of percentage defect in nugget

Table 4. Summary of regression model

\begin{tabular}{|c|c|c|}
\hline & & \multirow{2}{*}{253} \\
\hline \multirow{2}{*}{ Standard Error (S) } & \multirow{2}{*}{ R-Square (R-sq ) } & \\
\hline & & R-sq(adj) 254 \\
\hline 3.24762 & $84.77 \%$ & $77.61 \%$ \\
\hline
\end{tabular}

Table 5. Results of analysis of variance for the regression model

\begin{tabular}{|l|l|r|r|r|r|r|r|l|}
\hline Source & DF & SS & Contribution & Adj SS & Adj MS & $\begin{array}{l}\text { F- } \\
\text { Value }\end{array}$ & $\begin{array}{l}\text { P- } \\
\text { Value }^{\$}\end{array}$ & $\begin{array}{l}\text { F-ratio* } \\
\text { (calculated }\end{array}$ \\
\hline Regression & 8 & 909.32 & $84.77 \%$ & 909.322 & 113.665 & 11.14 & 0.000 & 11.14 \\
\hline $\mathrm{N}(\mathrm{rpm})$ & 1 & 571.22 & $53.25 \%$ & 35.768 & 35.768 & 3.50 & 0.080 & --- \\
\hline $\begin{array}{l}\mathrm{S} \\
(\mathrm{mm} / \mathrm{min})\end{array}$ & 1 & 115.52 & $10.77 \%$ & 6.819 & 6.819 & 0.67 & 0.426 & \\
\hline $\mathrm{O}$ (offset) & 1 & 58.32 & $5.44 \%$ & 22.116 & 22.116 & 2.17 & 0.160 & \\
\hline $\mathrm{N}^{2}$ & 1 & 56.70 & $5.29 \%$ & 56.700 & 56.700 & 5.55 & 0.032 & \\
\hline $\mathrm{S}^{2}$ & 1 & 20.63 & $1.92 \%$ & 0.476 & 0.476 & 0.05 & 0.832 & \\
\hline $\mathrm{O}^{2}$ & 1 & 0.06 & $0.01 \%$ & 22.344 & 22.344 & 2.19 & 0.158 & \\
\hline $\mathrm{NS}$ & 1 & 44.80 & $4.18 \%$ & 81.719 & 81.719 & 8.01 & 0.012 & \\
\hline $\mathrm{NO}$ & 1 & 42.08 & $3.92 \%$ & 42.076 & 42.076 & 4.12 & 0.059 & \\
\hline Error & 16 & 163.32 & $15.23 \%$ & 163.318 & 10.207 & & & \\
\hline Total & 24 & 1072.64 & $100.00 \%$ & & & & & \\
\hline
\end{tabular}




\subsection{Validation of the developed regression model}

260 Further validation experiments are conducted to verify the developed equation of regression model. Five number of friction stir weld joints are made using different conditions for the process parameters, which are other than the values used in L25 design matrix. The predicted response values and those obtained from the actual validation experiments are mentioned in Table 6. The deviation of predicted response values from the actual values is found to be less than $6 \%$, thus showing that the developed model go well with the experimental results.

Table 6. Results of validation experiments

\begin{tabular}{|l|l|l|l|l|l|l|}
\hline \multirow{2}{*}{$\begin{array}{l}\text { No. of } \\
\text { Trials }\end{array}$} & \multicolumn{3}{|l|}{ FSW parameters } & \multicolumn{2}{l|}{ \% Defect in Nugget Zone } & $\begin{array}{l}\text { Error = (Experimental - } \\
\text { Predicted) in \% }\end{array}$ \\
\cline { 2 - 6 } & $\mathrm{N}$ & $\mathrm{S}$ & $\mathrm{O}$ & Predicted & Experimental & \\
\hline 1 & 600 & 300 & -0.5 & 0.834 & 1.102 & 0.268 \\
\hline 2 & 1000 & 480 & 0.5 & 3.659 & 1.289 & -2.370 \\
\hline 3 & 1400 & 660 & 1.5 & 10.558 & 6.438 & -4.12 \\
\hline 4 & 1800 & 120 & -1.5 & 11.027 & 5.246 & -5.781 \\
\hline 5 & 1400 & 300 & -0.5 & 5.962 & 8.126 & 2.164 \\
\hline
\end{tabular}

\section{Results and Discussions}

\subsection{Appearance of weld joints}

The appearance of weld bead cross sections and top beads produced with different process parameters are presented in Figs. 3 and 4, respectively. It can be inferred from the figures that, defect free joints produced with tool rotational speed 400 to $2000 \mathrm{rpm}$, tool offset position $-2 \mathrm{~mm}$ to $+2 \mathrm{~mm}$ at $30 \mathrm{~mm} / \mathrm{min}$. The joints produced with rotational speed 400 to $800 \mathrm{rpm}$, welding speed 30 to $390 \mathrm{~mm} / \mathrm{min}$ and tool offset position $-2 \mathrm{~mm}$ to $+1 \mathrm{~mm}$ also resulted in sound joints. The defect free joints were produced at relatively high heat input due to extensive material intermixing as evidenced by macrographs (Fig. 3). It is well known that, heat input increases during friction stir welding with increasing tool rotational speed for a given tool travel speed, may result an increase in material tool contact area during welding which in turn helps in the formation of an enhanced metallurgical bond. Stirring effect of the pin becomes stronger at relatively higher tool rotational speeds (high heat input welds). Stronger stirring and much more softened material under high temperature, enhances the stir volume to overcome defects in the stir regions which also aids in stronger material intermixing. In addition to this, higher heat input will accelerate the inter diffusion between AA 5083 and AA 2219 which will help to form strong metallurgical bond. This phenomenon may be observed in the macrostructures of weld joints produced at tool traverse speed of $30 \mathrm{~mm} / \mathrm{min}$ with tool rotation speed varying from 400 to 2000rpm (Fig.3) and at different tool offset conditions. One of the important requirements of 
under the area of shoulder of the tool. This phenomenon is controlled by heat input during welding. As indicated in the literature, FSW process parameters influence the heat input. The heat input is directly proportional to tool rotation speed and inversely proportional to tool traverse speed. The wide range of similar and dissimilar alloys is successfully welded without defects by proper selection of friction stir welding process parameters [5, 6, 21-23].

The selection was made with reference to properties of base materials and flow behaviour of materials. The heat input during FSW is calculated by the following expression.

295 Heat input, $Q=T .\left(\frac{2 \cdot \pi \cdot N}{60}\right) \cdot S .1000$

296

297

298

299

300

301

302

303

304

305

306

307

308

309

310

311

312

313

314

315

316

Where, $\mathrm{Q}=$ heat input, $\mathrm{kJ} / \mathrm{mm}$

$\mathrm{N}=$ tool rotation speed, $\mathrm{rpm}$

$\mathrm{S}=$ tool traverse speed, $\mathrm{mm} / \mathrm{min}$.

$\mathrm{T}=$ toque on tool, $\mathrm{N}-\mathrm{m}$.

The above results can be explained further through the observed trends in the variations of axial force (force along Z-axis) (Fig. 5) on the pin with varying heat input. This force is a key parameter in controlling the metal flow in friction stir welding. As it is evident from Fig. 5, the axial force decreased with increasing heat input, indicating enhanced plasticity in the stirred zone. This is in tune with observed decrease in volume fraction of defects with heat input (Fig.6). From Figs. 5 and 6 it is clearly evident that at lower heat input conditions, the intermixing of dissimilar alloys is less though the defect is not present in nugget zone. Whereas at higher heat input conditions, zero \% defect is noticed in association with extensive intermixing of alloys. An increasing trend in $\%$ defect at intermediate heat input conditions compared to lower heat input conditions could be due to the dissimilarity that exists in the physical properties of both alloys. The reasons for the formations of these defects are further explained in the forthcoming sections. The formation of un-bonded region could be related to the relatively low heat input which in turn led to inadequate plasticity confined to immediate vicinity of the pin mainly due to large amount of material being deformed with high flow strength. 

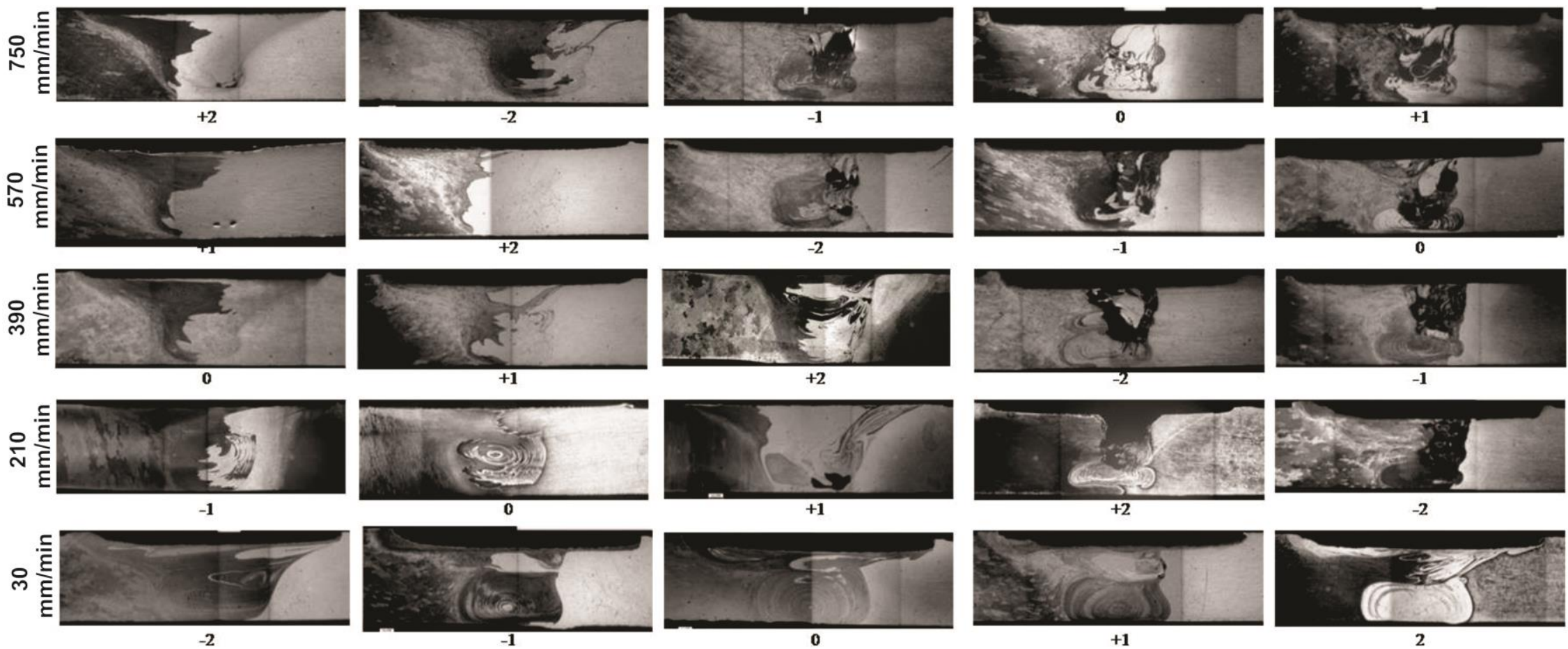

$400 \mathrm{rpm}$

$800 \mathrm{rpm}$

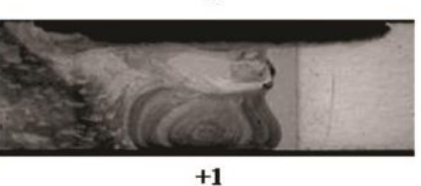

$1600 \mathrm{rpm}$

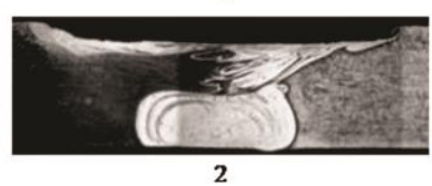

$2000 \mathrm{rpm}$

Fig. 3. Optical macrographs of the FS weld joints at different welding parameters (The numbers below macrostructure indicate tool axis offset: positive is towards AA5083 alloy side and negative is towards AA 2219 alloy side) 


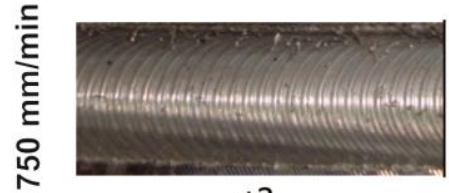

$+2$

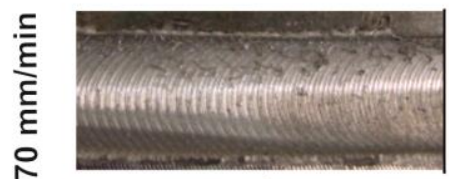

$+1$

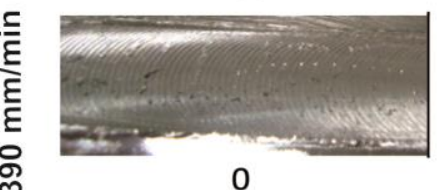

0

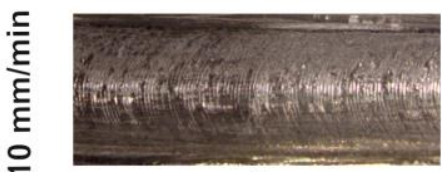

$-1$

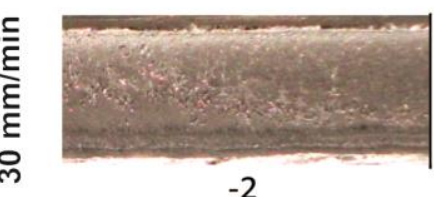

400 rpm

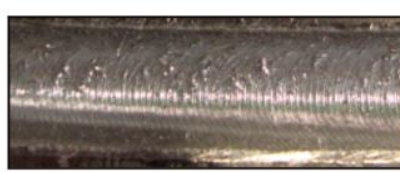

$-2$

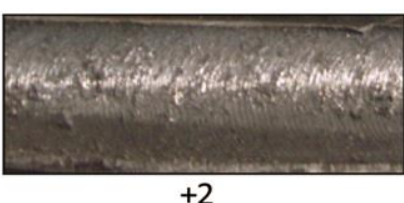

$+2$

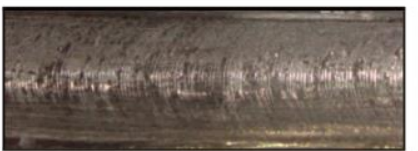

$+1$

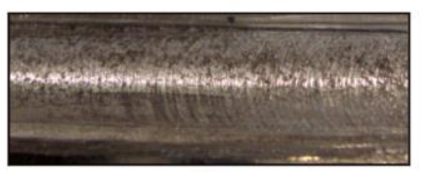

0

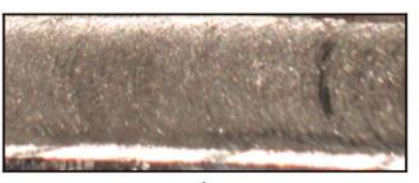

800 rpm

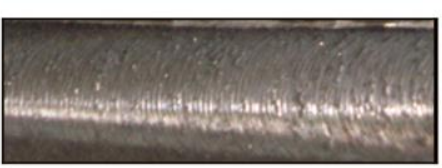

$-1$
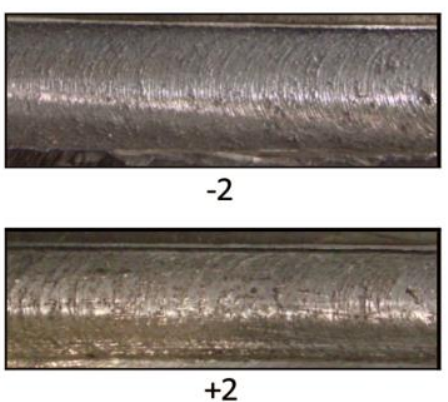

$+2$

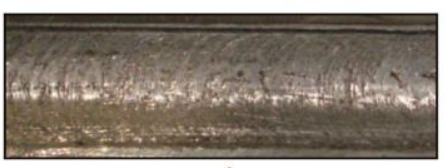

$+1$

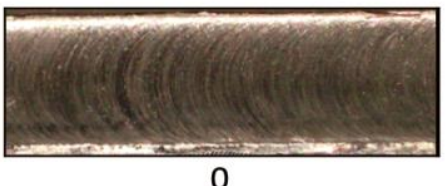

$1200 \mathrm{rpm}$

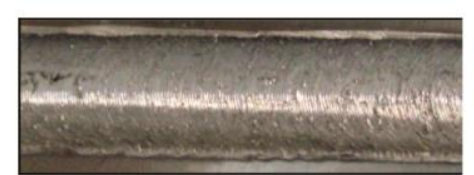

0
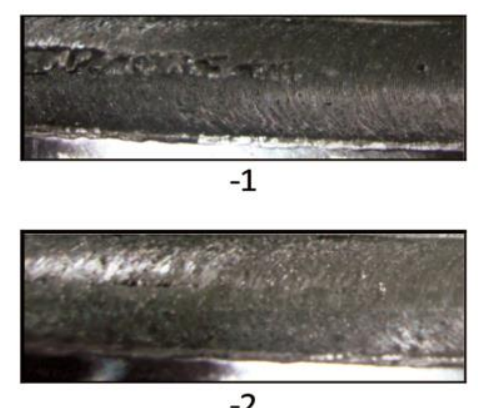

$-2$

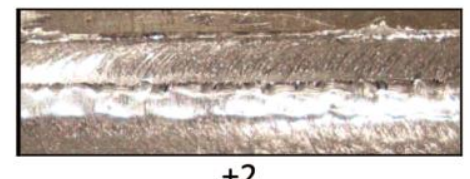

$+2$

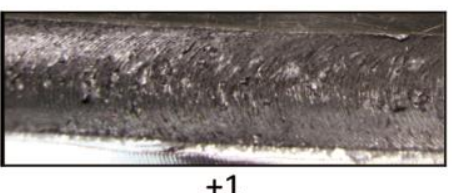

$1600 \mathrm{rpm}$

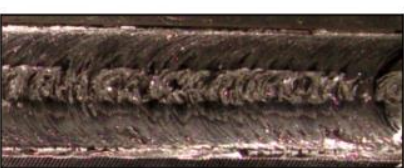

$+1$
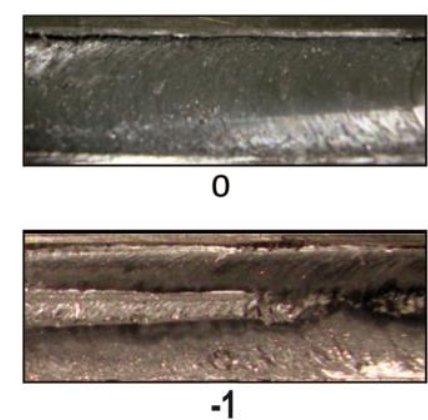

$-1$
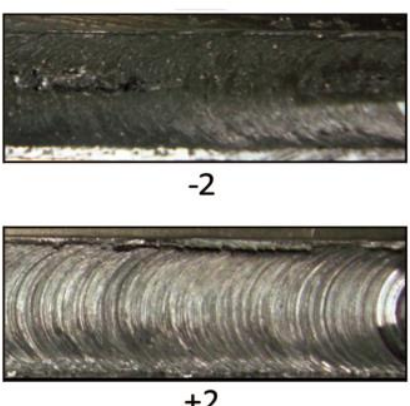

$2000 \mathrm{rpm}$

Fig. 4. Top bead appearance of the FS weld joints at different welding parameters (The numbers below macrostructure

323 indicates tool axis offset positive is towards AA2219 side and negative is towards AA 5083 side) 


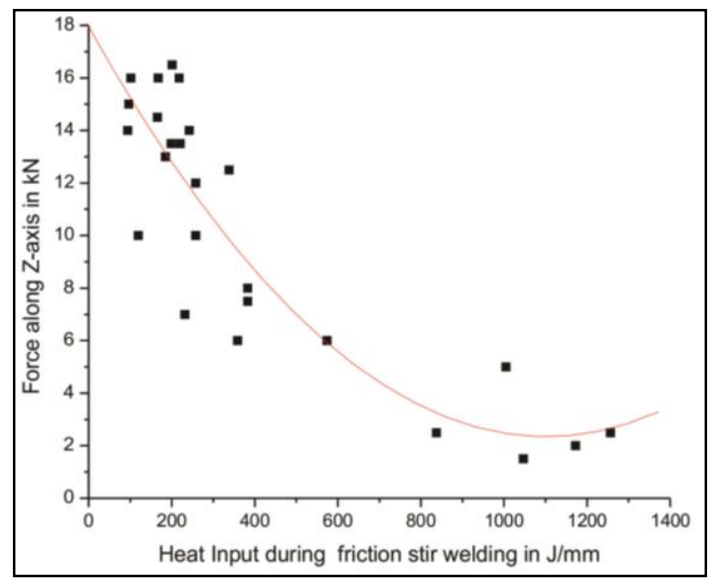

Fig. 5. The variation of $\mathrm{Z}$-axis load versus heat input during friction stir welding

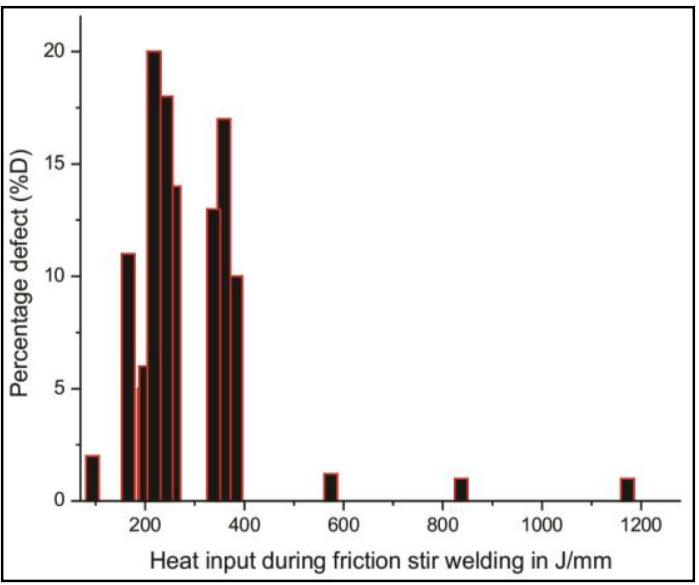

Fig.6. The variation of percentage defect $(\% \mathrm{D})$ versus heat input during friction stir welding

\subsection{Variation of \% defect area with welding parameters}

In order to determine the processing values that give optimum response, three dimensional plots were used along with corresponding contour diagram. Both of these were plotted as response Vs any two processing parameters, while keeping remaining processing parameter constant (equal to constant value as indicated in the respective plot).

The surface and contour plots for \% defect area with respect to tool offset and tool traverse speed are shown in Fig. 7. The surface plot depicts gradual increase in $\%$ defect as the traverse speed was increased with a tool offset towards the AA2219 alloy side. It can be deduced from the plot that a minimum defect could be achieved when tool offset was around 1mm towards AA 5083 alloy side and the traverse speed was kept at its least possible value.

The surface and contour plots of $\%$ defect versus tool offset and tool rotation speed are shown in 
341 speed with a tool offset towards the AA2219 alloy side. The minimum \% defect occurred at an 342 approximate tool offset of $0.5 \mathrm{~mm}$ towards AA 5083 alloy side and $2 \mathrm{~mm}$ towards AA

343 2219alloy side keeping the rotation speed at 400rpm.
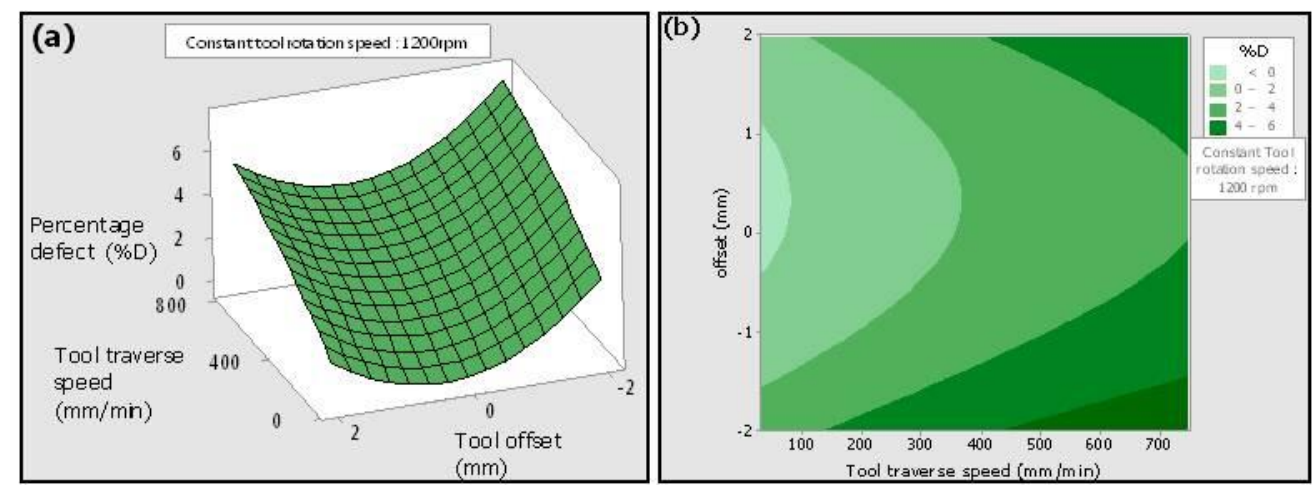

Fig. 7 (a) Surface plot and (b) contour plot of percentage defect (\%D) versus tool traverse 346 speed and tool offset
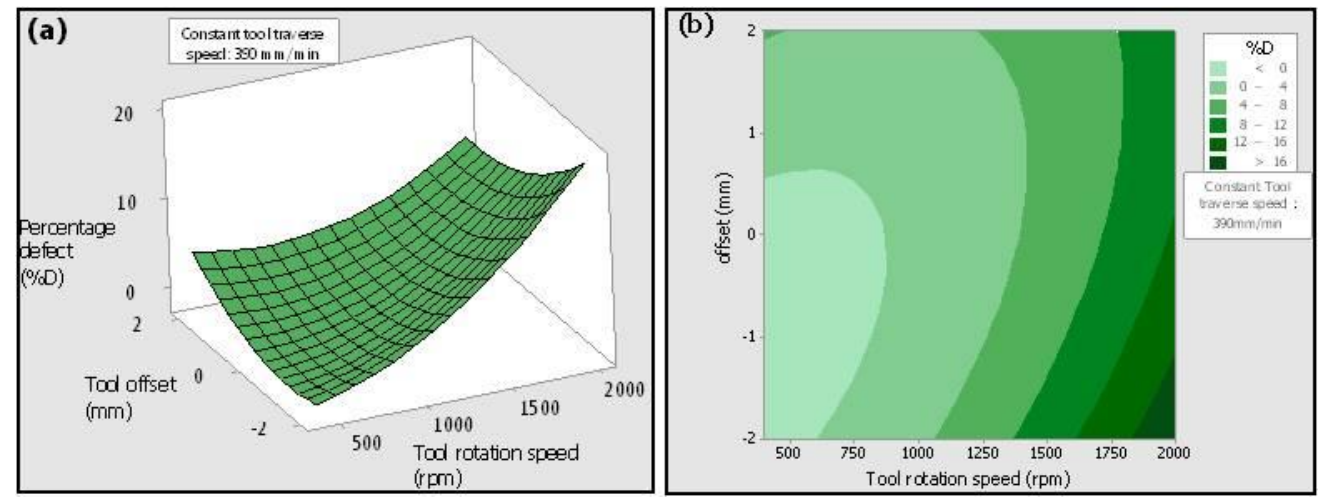

Fig. 8. (a) Surface plot and (b) contour plot of percentage defect (\%D) versus tool rotation speed and tool offset
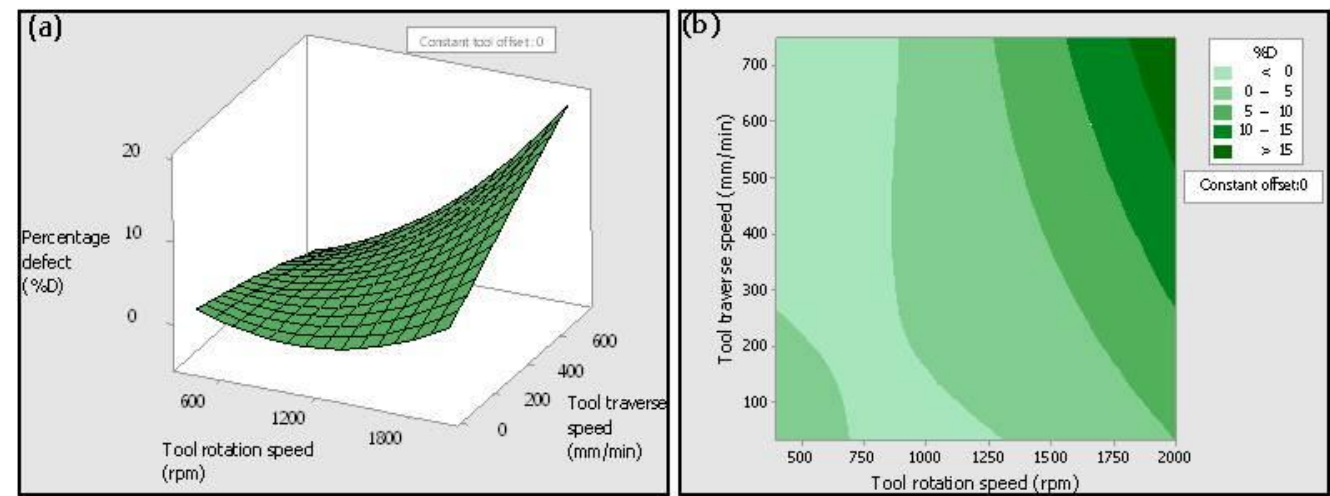

351 Fig. 9 (a) Surface plot and (b) contour plot of of percentage defect (\%D) versus tool 352 traverse speed and tool rotation speed 
The surface and contour plots (Fig. 9) for \% defect area with respect to tool rotation speed and tool traverse speed shows a very gradual increase in \% defect when the traverse speed was kept below $300 \mathrm{~mm} / \mathrm{min}$ with rotational speed below 800rpm. At higher tool rotation speed and traverse speed the \%defect increased. The contour plot indicates that initially the slope of the increase in \% defect was high once the rotational speed increased above $1200 \mathrm{rpm}$. One can easily observe that a minimum defect could be achieved by keeping traverse speed above 300 $\mathrm{mm} / \mathrm{min}$ and the rotational speed between 800 and $1200 \mathrm{rpm}$.

At higher tool rotation speed, lower traverse speed and tool offset towards AA2219 alloy side increased the $\%$ defect. This can be explained as AA 2219 alloy is strengthened by precipitation hardening mechanism which is strongly time and temperature dependent. Above $250^{\circ} \mathrm{C}$, the precipitates are unstable and dislocation density also reduces, thus causing a rapid decrease in flow stress above this temperature [19]. In contrast AA5083 is predominantly strengthened by a sold solution of magnesium and displays a more gradual decrease in flow stress $[18,19]$. In the present investigation, high temperature, obtained at higher tool speed led to softening of AA2219 alloy. Softened material at high temperature produced less shearing to transport material. This led to considerable turbulence, which affected the material flow behavior and resulted in defective welds.

\subsection{Effect of process parameters on inter-mixing}

Macrographs of cross section of defect free welds are shown in Fig.10, to understand the role of tool offset and travel speed at constant tool rotation speed $(800 \mathrm{rpm})$ on the extent of intermixing of materials during welding. It can be seen that at extreme tool offset, viz-a-viz, $2 \mathrm{~mm}$ towards AA5083 (Fig. 10(a)) or towards AA2219 (Fig. 10(e)) resulted in relatively low level of intermixing. This was because more heating in one side of the interface resulted in considerable differences in viscosities of both materials. The similar type of observations were seen with 1 mm offset towards AA5083 (Fig. 10(b)) and towards AA 2219(Fig. 10(d)), i.e., mixing was better when tool was offset toward AA2219. Moreover the $+/-1 \mathrm{~mm}$ offset offered better mixing compared to $+/-2 \mathrm{~mm}$ offset. Extensive intermixing was observed when tool is aligned to the joint centre line (Fig 10(c)). As the welding temperature approaches the solidus temperature of an alloy, the material softens, slip occurs and less energy is transferred to work piece. 


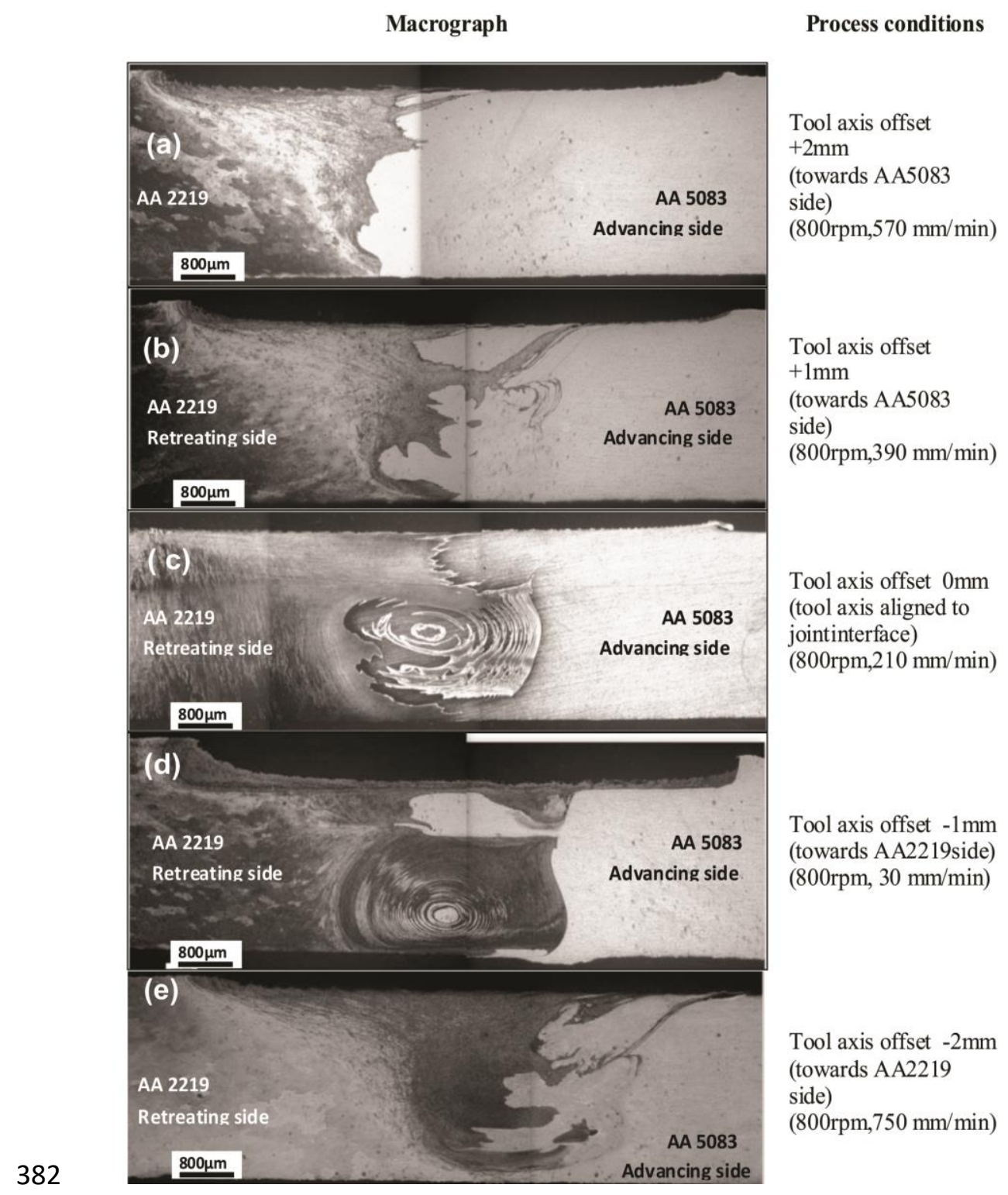

383 Fig. 10. Macrostructures showing the effect of tool offset on material flow in dissimilar 384 friction stir weld

386 It is important to note that solidus temperature of AA5083 alloy $\left(574^{\circ} \mathrm{C}\right)$ is more compared to 387 that of AA2219 alloy $\left(543^{\circ} \mathrm{C}\right)$; therefore, under same welding conditions the transfer of energy 388 between the tool and work piece, was more efficient in AA5083 alloy than AA2219 alloy. 389 Hence, the maximum temperature for a given energy level increases with increasing solidus 390 temperature, this might result more mixing of AA5083 alloy. In addition to this, flow strength of 391 AA2219 alloy is quite low as compared to AA5083 alloy [18,19] might result in less mixing of 392 AA2219 alloy (Fig. 10 (b) and(c)). It can be seen that though the tool is offset towards AA5083 393 or positioned at the joint centre line, a good amount of AA2219 was mixed into AA5083. This 
macrostructure suggests that sufficient frictional heat was generated to plasticize both alloys.
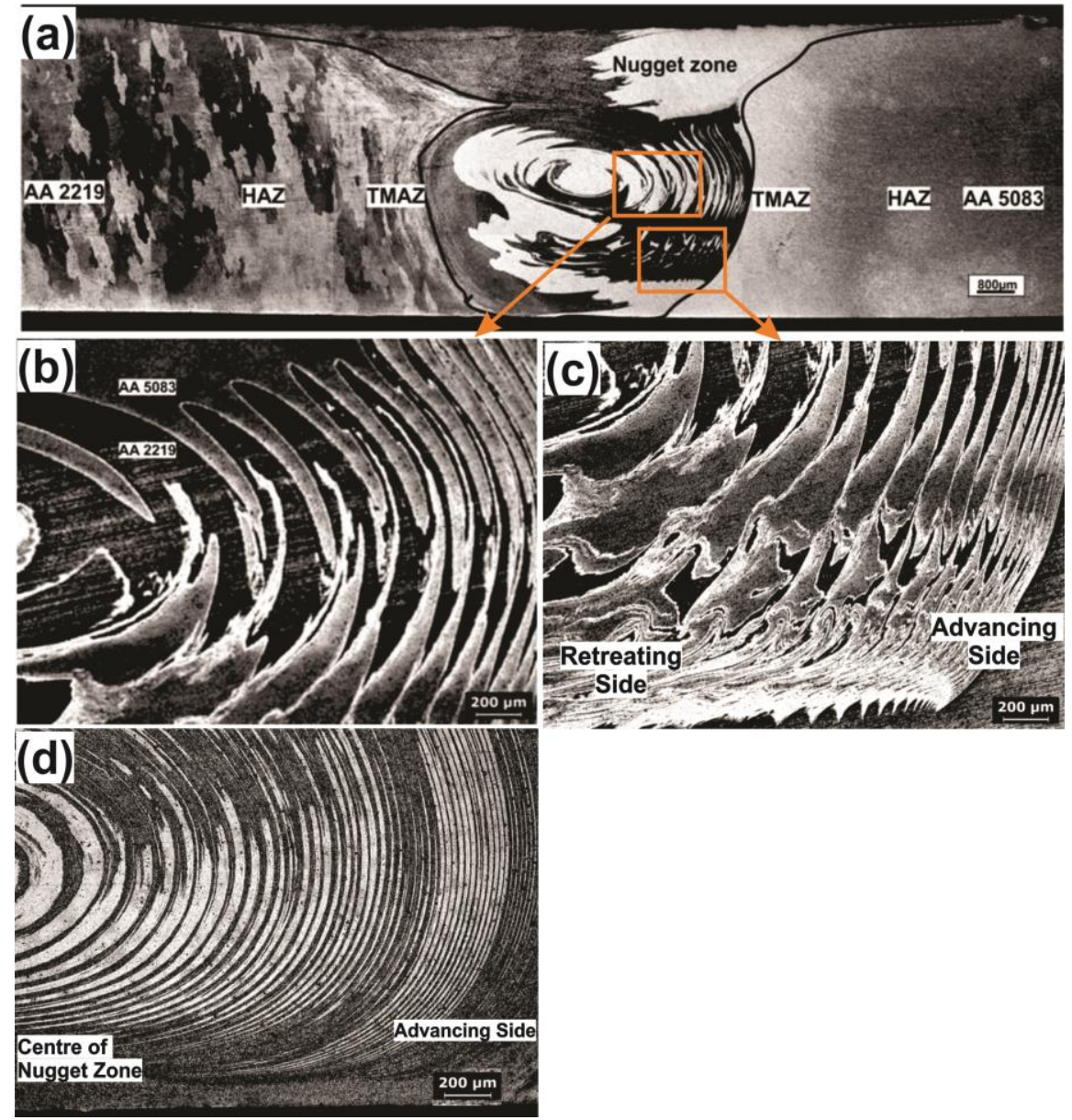

Fig. 11. (a) Optical macrograph of the FS weld joint made with welding parameters 800rpm, $210 \mathrm{~mm} / \mathrm{min}$, tool axis aligned to joint interface. (b) and (c) are different zones at advancing side at higher magnification (d) Onion rings of weld joint made with parameters 800rpm, 30mm/min and $1 \mathrm{~mm}$ tool-offset towards AA2219 alloy side.

Off-set is an important process parameter to achieve defect free welds in dissimilar metal joints speed and tool traverse speed. Tool offset is inevitable to bring the comparable flow stress levels, by generating a relatively greater proportion of heat in the stronger material through appropriate tool off-set. intermixing of material was more as the tool rotation speed increased with tool offset towards AA5083 alloy side. With stronger stirring due to high tool rotation speed, much more softened material under high temperature might lead to increase in volume of stirred material which resulted in extensive mixing. 
Low traverse speed also enhanced intermixing of both dissimilar materials in nugget zone by increasing residence time, which counter-acted against the differences in viscosities of both materials. Similar observation was reported by Izadi et al., [24] during friction stir welding of AA2024-T351 alloy to AA 6061-T6. The observation can be corroborated from the macrographs in Fig. 10.Welds produced at tool traverse speed at $30 \mathrm{~mm} / \mathrm{min}$ (Fig. 10(d)) and $210 \mathrm{~mm} / \mathrm{min}$ (Fig. 10(c)) showed better mixing in form of alternate layers of dissimilar materials termed as onion rings.
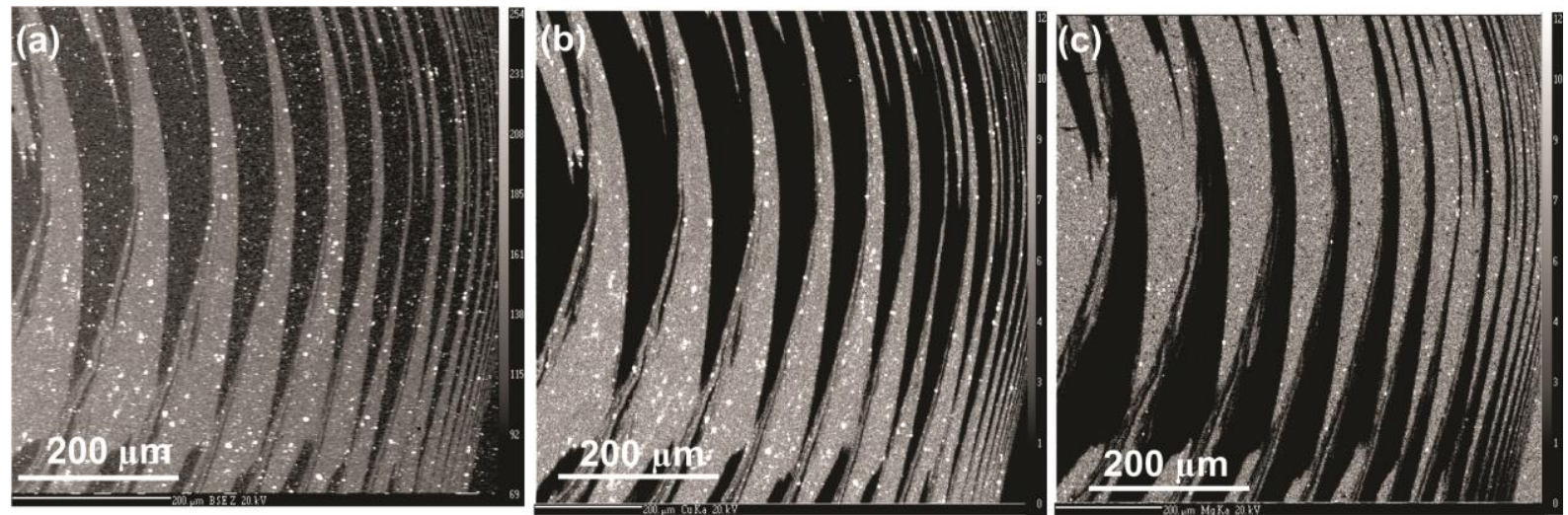

Fig. 12.(a) Back scattered image of dissimilar friction stir weld joint produced at

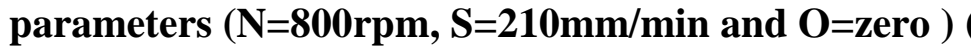
(b) elemental mapping of magnesium (c) elemental mapping of copper

The high magnification macrographs of Fig 10(c) are, shown in Figs. 11(a), (b) and (c), clearly illustrates the banded structure consisting of lamellae of AA2219 and AA5083 alloys. The light etched layers are of AA5083 alloy whereas dark etched zones corresponds to AA2219 alloy. This fact can be noticed from the back scattered image of dissimilar weld joint shown in Fig 12(a). The light and dark etched layers in Fig 12(a) correspond to the elemental mapping of magnesium (light etched layers in Fig 12(b)) and elemental mapping of copper (light etched layers in Fig 12(c)) respectively. Formation of laminated structure near the AA5083 alloy side occurred more frequently than AA2219 alloy side, and this may be attributed to the relation between the welding direction and tangential component of the rotation of the tool. The directions of welding and tool rotation were the same on the advancing side, while they were in opposite on the retreating side. Thus steeper gradient of plastic strains are caused by the severe plastic deformation. In addition, the stable deformation of AA5083 alloy (due to its high flow strength) than AA2219 alloy resulted in the formation of laminated structure on the advancing side. It is clearly evident from Fig.11 (d) that the spacing and width between the alternate layers increased while moving from advancing side to retreating side. This could be due to the fact that the velocity of material sticking to tool pin surface was higher in advancing side compared to that of in the retreating side. So as the residence time for each layer was smaller at advancing side, the inter layer spacing was less while there was no enough time available for consolidation, thus the layer thickness was also lesser at advancing side. When the traverse speed was further increased to $390 \mathrm{~mm} / \mathrm{min}$ at the same tool rotation speed of $800 \mathrm{rpm}$ with $1 \mathrm{~mm}$ tool axis offset 
towards AA5083 side (Fig 10(b)) a clear curvy and zig-zag interface separating both dissimilar materials in place of onion rings can be seen. The curviness of the zig-zig interface further reduced and a distinct $S$-shaped wavy interface formed when the traverse speed was increased to $570 \mathrm{~mm} / \mathrm{min}$ at a tool offset of $2 \mathrm{~mm}$ towards AA5083 alloy side, as shown in Fig. 10(a). But at the same tool offset condition of $2 \mathrm{~mm}$ towards AA5083 alloy side and with the increased tool rotation speed of $2000 \mathrm{rpm}$ and reduced traverse speed of $30 \mathrm{~mm} / \mathrm{min}$, the nugget zone exemplified thorough intermixing of two dissimilar alloys as shown in Fig. 13(e).

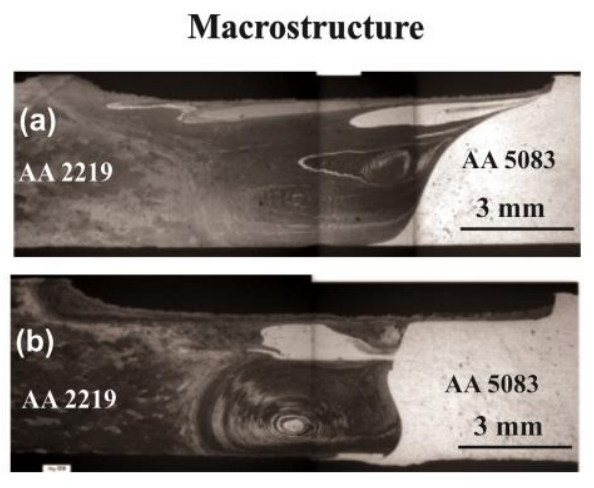

\section{Welding Paramete}

Tool axis offset $-2 \mathrm{~mm}$ (towards AA2219 side) (400rpm, $30 \mathrm{~mm} / \mathrm{min}$ )

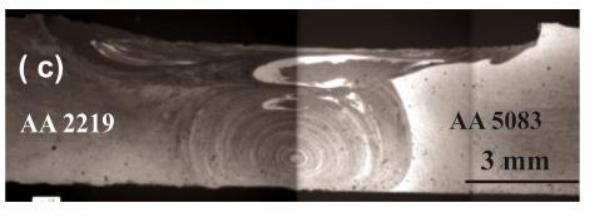

Tool axis aligned joint line (1200rpm,30 mm/min)

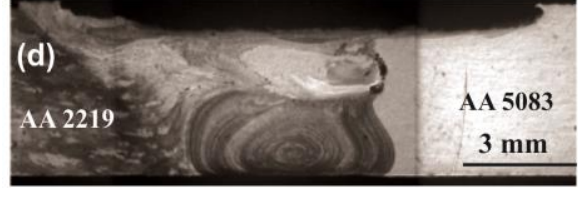

Tool axis offset $+1 \mathrm{~mm}$ (towards AA5083 side) (1600rpm,30 mm/min)

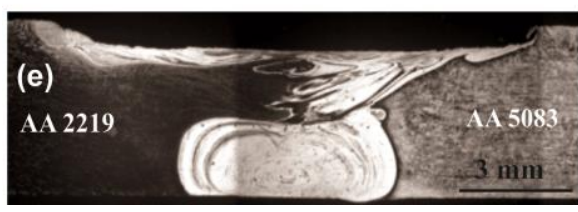

Tool axis offset $+2 \mathrm{~mm}$ (towards AA5083 side) (2000rpm,30 mm/min)

Fig. 13. Optical macrographs dissimilar welds of high heat input conditions and corresponding fracture locations of tensile specimens

It is clearly evident from Fig.13(a) to (e) that, at all the high heat input welding conditions (i.e., at all rotation speeds and at low traverse speed, $30 \mathrm{~mm} / \mathrm{min}$ ), intimate mixing of two alloys has occurred in the nugget zone. The Fig. 14 depicts back scattered image and elemental mapping of copper and magnesium in the dissimilar weld joint produced with process parameters of tool rotation speed of $1200 \mathrm{rpm}$, tool traverse speed of $30 \mathrm{~mm} / \mathrm{min}$ and zero tool offset. The elemental mapping shown in Fig. 14(a) indicates that both the dissimilar alloys were thoroughly mixed at the high heat input conditions. The contour plot of $\%$ area defect versus heat input and tool-offset shown in Fig. 15 also re-affirms this observation. The welding parameters contributing to welding heat more than $2.5 \mathrm{~kJ} / \mathrm{mm}$ have produced weld joints with less than $1 \%$ defect, 

lower traverse speeds the tool stayed for a longer time at any location of weld joint and

462 resultedin intimate mixing both alloys.
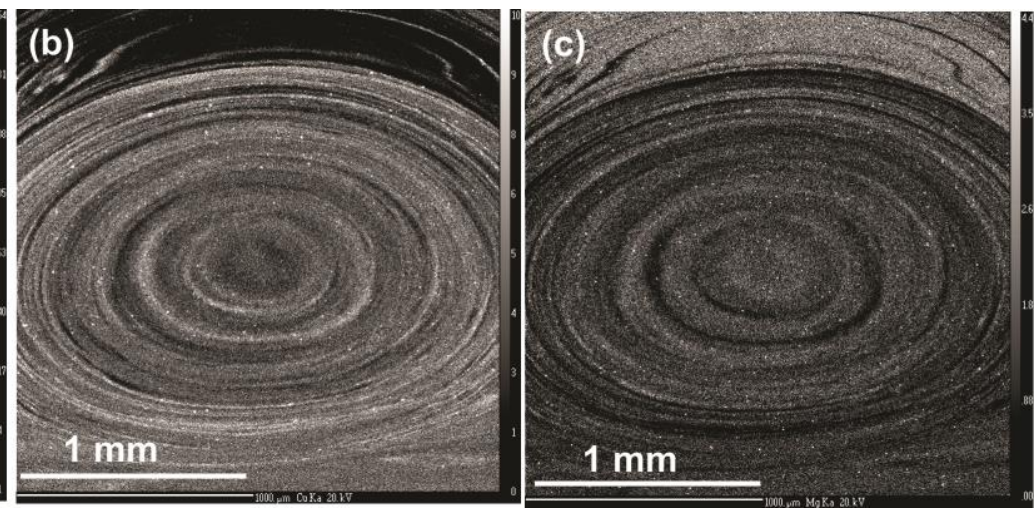

Fig.14 (a).Back scattered image of dissimilar friction stir weld joint produced at parameters $(\mathrm{N}=1200 \mathrm{rpm}, \mathrm{S}=30 \mathrm{~mm} / \mathrm{min}$ and $\mathrm{O}=$ zero) (b) elemental mapping of Copper (c) elemental mapping of magnesium

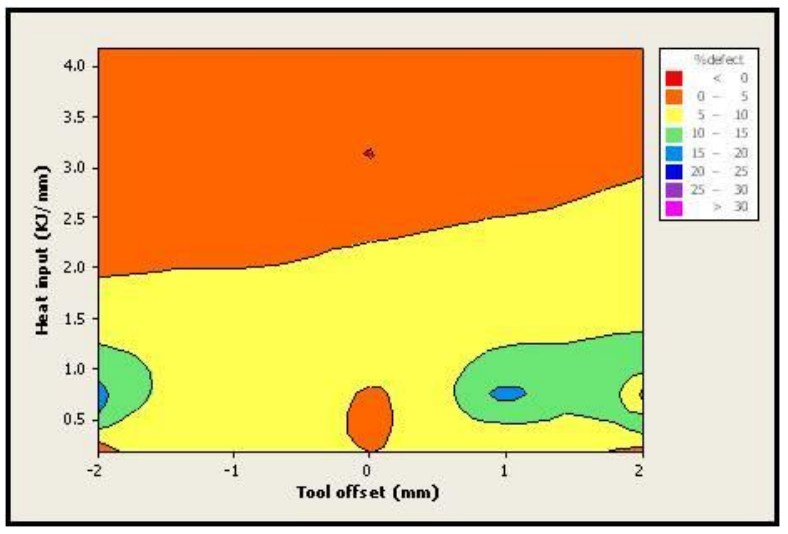

Fig. 15. The contour plot of \%defect of dissimilar welds versus heat input per $\mathrm{mm}$ of weld length and tool offset.

During friction stir welding, the bonding between the transferred material from leading edge and material that exist in the trailing can occur only when they are brought together in the vicinity of inter-atomic forces over the area of contact. When the rotating pin progresses along the joint line, the surface of two pieces are dragged in to shear zone, thus breaking up brittle surface oxides Adequate contact can be attained by the application of compressive stress developed in the weld nugget region due to axial load. The hydrostatic pressure that is developed in the weld nugget should be essentially higher than the flow stress of the materials of the mating surfaces. Since flow stress reduces as temperature increases, force required to make the adequate contact between the surfaces decreases. Hence the formation of defect free joints in solid state requires optimum temperature and hydrostatic pressure. When the axial load and heat input continuously increased the hydrostatic pressure and the temperature in the weld region continuously increases 
482 along the weld, and at an optimum temperature and pressure defect free welds is formed

483 automatically for a given set of parameters. The effect of process parameters on weld defect and

484 intermixing pattern can be noticed on the mechanical properties as described next.

\section{$485 \quad 4.4$ Microhardness}

486 The typical variation of microhardness along the mid thickness of transverse cross section across

487 the weldment produced with parameters $800 \mathrm{rpm}, 210 \mathrm{~mm} / \mathrm{min}$, tool axis exactly aligned with

488 joint centre line is shown in Fig. 16(a). The hardness of AA2219 base material was substantially

489 higher than that of AA5083 base material. As can be seen, there was a drop in the hardness in the

490 HAZ on retreating side compared to the un-affected AA2219 base material. A similar trend was

491 observed in HAZ towards advancing side compared to the unaffected AA5083 alloy base

492 material. The hardness of nugget zone was found to be significantly lower than that of AA2219

493 base material and slightly higher than the AA5083 base material. The reduction in hardness in

494 HAZ of AA2219 alloy side could be due to dissolution or coarsening of $\mathrm{Al}_{2} \mathrm{Cu}$ precipitates due

495 to the exposure to welding heat input. Similarly the drop of hardness in HAZ of AA 5083 alloy

496 side can be correlated to the loss of cold working / softening due to decreased dislocation density

497 during FSW thermal cycle.

498 Interestingly, it is observed that the hardness in the nugget zone switched from peak to lower 499 values alternatively corresponding to the alternate layers of dissimilar materials. It was noticed 500 that higher hardness value belongs to AA5083 layer while the lower hardness corresponds to 501 AA2219 layer. This fact can be noticed from the indents shown in the high magnification optical 502 macrographs of the onion rings as shown in Fig. 16 (b) and (c). A similar observation was 503 reported by Ouyang et al., [25] in the case of dissimilar friction stir welds of AA2024-T3 and 504 AA 6061-T6. The lower hardness in the layer of AA2219 could be due to the complete 505 dissolution of precipitates whereas the higher hardness of the AA5083 layer could be due to the 506 strain hardening of AA5083 material occurring due to the severe plastic deformation during 507 stirring. 

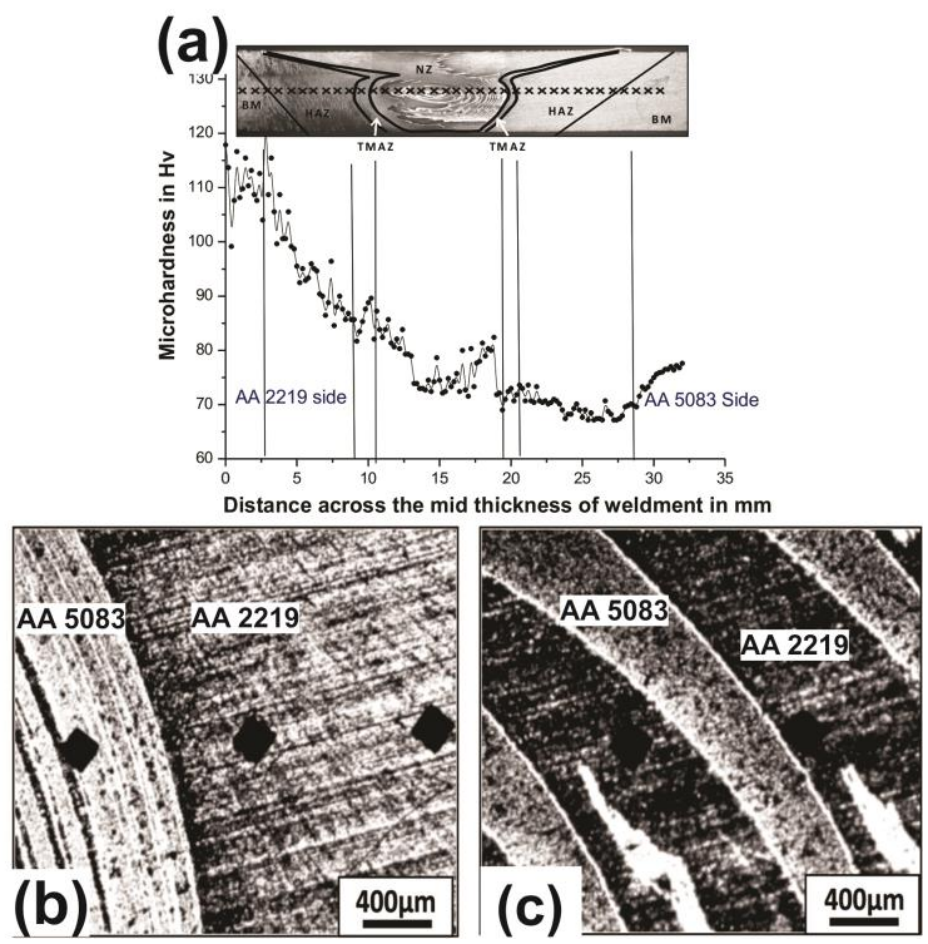

512 Fig. 16.Microhardness survey across a typical FS weld joint made with welding parameters $800 \mathrm{rpm}, 210 \mathrm{~mm} / \mathrm{min}$, tool axis aligned to joint interface. (a) and (b) are indentations on alternate layers in nugget zone at higher magnification.

\subsection{Tensile Properties and bend test results}

517 The presence of defects in weld nugget directly influenced the strength of the weld joint. The tensile strength and fracture location of the joints were to a large extent, dependent on the process parameters. When joints were associated with defects (tunnels, cracks and pin holes) transverse tensile specimens failed at the defective area and on the other hand when the joints were free of defects, the tensile properties of the joint depended only on the lowest hardness region of the weldment.

The transverse tensile properties of defect free joints and the corresponding joint efficiencies (calculated based on ultimate tensile strength of weaker base material) are listed in Table 7. Highest joint strength was achieved for the dissimilar weld produced with $800 \mathrm{rpm}, 210 \mathrm{~mm} / \mathrm{min}$ and zero offset, where it is close to tensile strength of AA5083 ( 97\%), while the joint made with parameters $800 \mathrm{rpm}, 570 \mathrm{~mm} / \mathrm{min}$ and $2 \mathrm{~mm}$ offset towards AA5083 side, showed the lowest strength. The typical transverse tensile stress versus strain plots for the fully mixed dissimilar weld joint (800rpm, $210 \mathrm{~mm} / \mathrm{min}$ and zero tool offset) and those of corresponding base materials are shown in Fig. 17. The fractured tensile test specimens of weld joints are shown in Fig.18.

531 One can easily deduce from Fig 17 that the fully mixed dissimilar weld joint possess the tensile 532 strength and \% elongation in between those of both the base materials. 
533 Table 7. The transverse tensile properties of dissimilar friction stir welds of AA2219 and $534 \quad$ AA5083 aluminum alloys

\begin{tabular}{|l|l|l|l|l|l|l|l|l|}
\hline $\begin{array}{l}\text { Tool } \\
\text { rotation } \\
\text { speed } \\
(\mathrm{rpm})\end{array}$ & $\begin{array}{l}\text { Tool } \\
\text { traverse } \\
\text { speed } \\
(\mathrm{mm} / \mathrm{min})\end{array}$ & $\begin{array}{l}\text { Tool } \\
\text { axis } \\
\text { offset } \\
(\mathrm{mm})\end{array}$ & $\begin{array}{l}\text { UTS } \\
\text { (MPa) }\end{array}$ & $\begin{array}{l}0.2 \% \\
\text { PS } \\
(\mathrm{MPa})\end{array}$ & $\begin{array}{l}\% \\
\text { El. }\end{array}$ & $\begin{array}{l}\text { Joint } \\
\text { Efficiency } \\
\text { on UTS }\end{array}$ & $\begin{array}{l}\text { Intermixing of } \\
\text { both alloys in } \\
\text { nugget zone }\end{array}$ & $\begin{array}{l}\text { Failure } \\
\text { Location }\end{array}$ \\
\hline 800 & 210 & 0 & 297 & 172 & 8.8 & 97.05 & Good & $\begin{array}{l}\text { HAZ of AA } \\
5083 \text { alloy } \\
\text { side }\end{array}$ \\
\hline 800 & 570 & +2 & 277 & 157 & 5.0 & 90.52 & Bad & $\begin{array}{l}\text { Nugget } \\
\text { Zone along } \\
\text { zig-zag } \\
\text { interface }\end{array}$ \\
\hline 1200 & 30 & 0 & 290 & 155 & 7.6 & 94.77 & Good & $\begin{array}{l}\text { HAZ of AA } \\
5083 \text { alloy } \\
\text { side }\end{array}$ \\
\hline
\end{tabular}

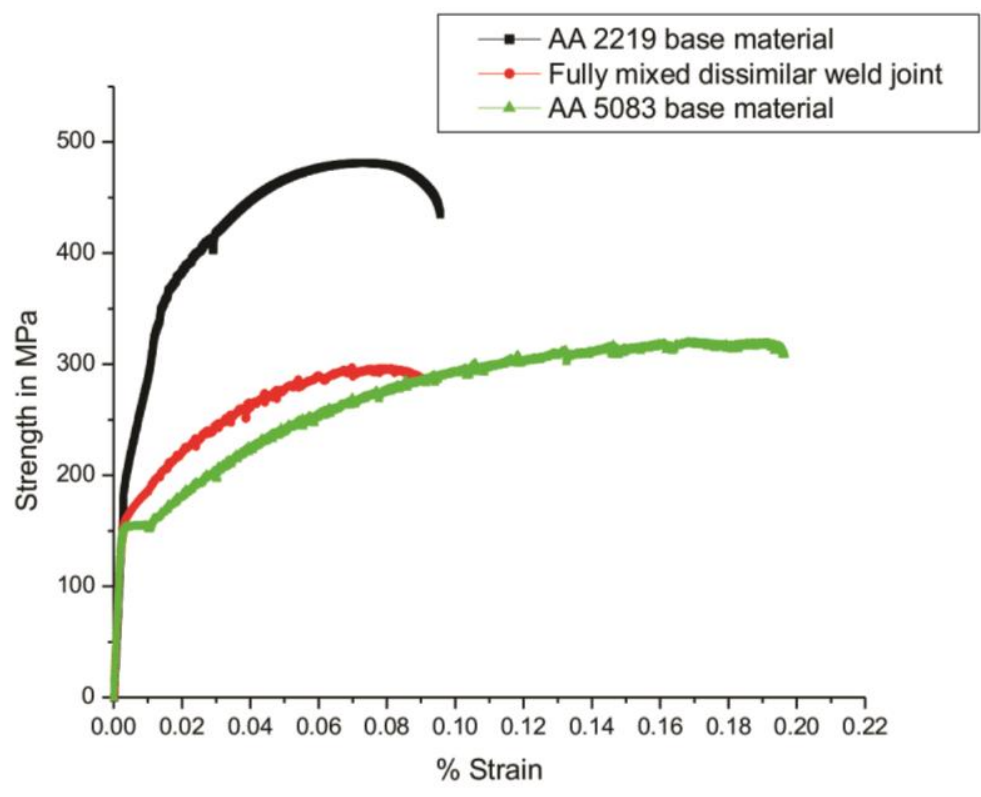

537 Fig.17. The tensile stress versus strain plots of both base materials, partially mixed and 538 fully mixed dissimilar weld joints 


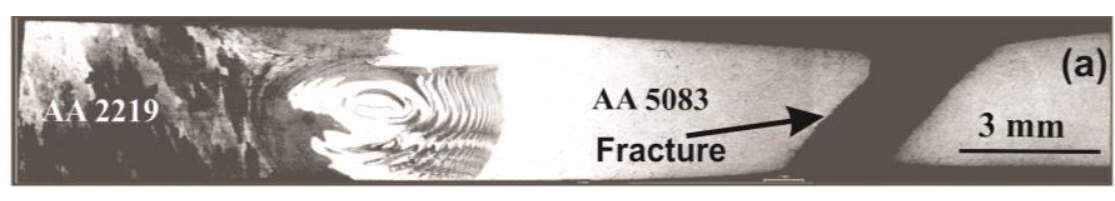

800rpm

$210 \mathrm{~mm} / \mathrm{min}$

Zero offset

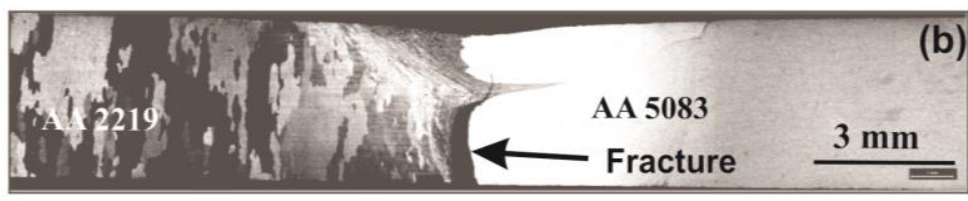

$800 \mathrm{rpm}$

$570 \mathrm{~mm} / \mathrm{min}$

$2 \mathrm{~mm}$ offset

towards AA5083

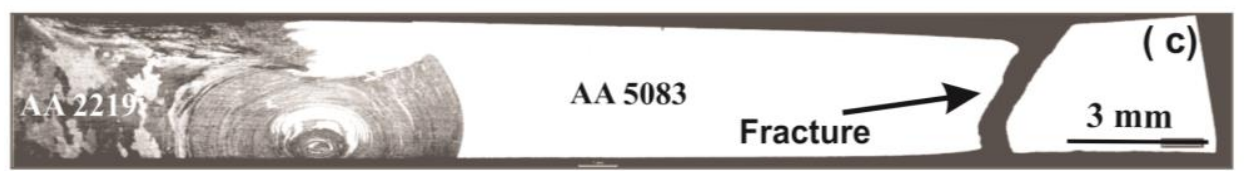

1200rpm

$30 \mathrm{~mm} / \mathrm{min}$

Zero offset

Fig. 18. The fractured transverse tensile specimens of dissimilar friction stir welds of AA2219 and AA5083 alloys depicting different failure locations

During tensile testing the deformation was concentrated in the heat affected zone of AA5083 alloy, in most cases the failure confined to this region. The exception was weld made with parameters $800 \mathrm{rpm}, 570 \mathrm{~mm} / \mathrm{min}$ and $2 \mathrm{~mm}$ offset towards AA5083 side which failed at the weld joint line (Fig. 18) due to insufficient AA5083/AA2219 intermixing and poor inter diffusion at the bottom region of the faying surfaces. This may be due to the reduced temperature caused by less AA2219/tool interaction caused because of complete offset towards AA5083 alloy side. This might have resulted in low AA2219/tool contact area which led to reduced flowability of AA2219 alloy. This was manifested in straight faying surfaces at the bottom of joint. Probably the pre-existing oxides at these faying surfaces might be intact during welding. The low weld temperature and intact oxide films would have reduced the inter diffusion across the AA5083/AA2219 resulting in a weak bond.

The factors which govern the tensile strength of dissimilar aluminium alloys are (i) presence of defects in the weld zone (ii) degree of plastic flow and amount of mixing of both the materials (iii) degree of dissolution and over aging of precipitates. A dissimilar weld can be considered as a good weld, when the failure takes place in the weaker of the two dissimilar materials away from the weld zone. The tensile specimen belonging to zero offset condition fractured in HAZ of AA5083 alloy with strength and \% elongations significantly higher than those of other specimens. A noteworthy intermixing of two dissimilar alloys was found in nugget zone in case of specimen with zero tool offset condition. Nugget zone fracture was observed for the specimen in which the tool was shifted towards AA5083 alloy by $2 \mathrm{~mm}$. The nugget zone of this specimen showed a distinct separating zig-zag shaped interface between the two alloys and the

564 interestingly the fracture is found to be initiated along this zig-zag interface (Fig.10 (a) and 565 18(b)). The zig-zag interface could have easily given way for the initiation and propagation of 566 crack under tensile loading, as the two dissimilar alloys on both sides of this interface possess 
different yield strength and elongations. Whereas in case of specimen with good intermixing of two materials in nugget zone, the alternately placed layers yielded collectively under the tensile loading and the failure location shifted to HAZ of AA5083 alloy instead of nugget zone.

As a whole, it was noticed that, irrespective of tool offset conditions, the tensile specimens with good intermixing of two materials in nugget zone have fractured in the minimum hardness region in HAZ of AA5083 alloy. The fracture in HAZ of AA5083 alloy can be correlated to the inferior micro hardness in the zone compared to other regions of the weldment, which was in turn a resultant of loss of cold working or softening because of exposure to high temperatures caused due to welding heat. So, in order to achieve better joint strength of dissimilar aluminum alloy friction stir weld, one should always aim for arriving at the welding parameters which will create conditions that favor the intimate mixing of both dissimilar aluminum alloys in nugget zone.

The bend tests for the welds joints for fully mixed and partially mixed dissimilar metal joints were conducted mainly to assess the ductility and toughness of weldments. The face bend test samples of dissimilar friction stir welds after bend testing are shown in Fig. 19. Face bend test of the extensively mixed dissimilar friction stir weld joint passed the $90^{\circ}$ bend angle without resulting in any crack at the root. Whereas the partially mixed weld fractured along the interface of the two dissimilar alloys in the root / nugget zone.

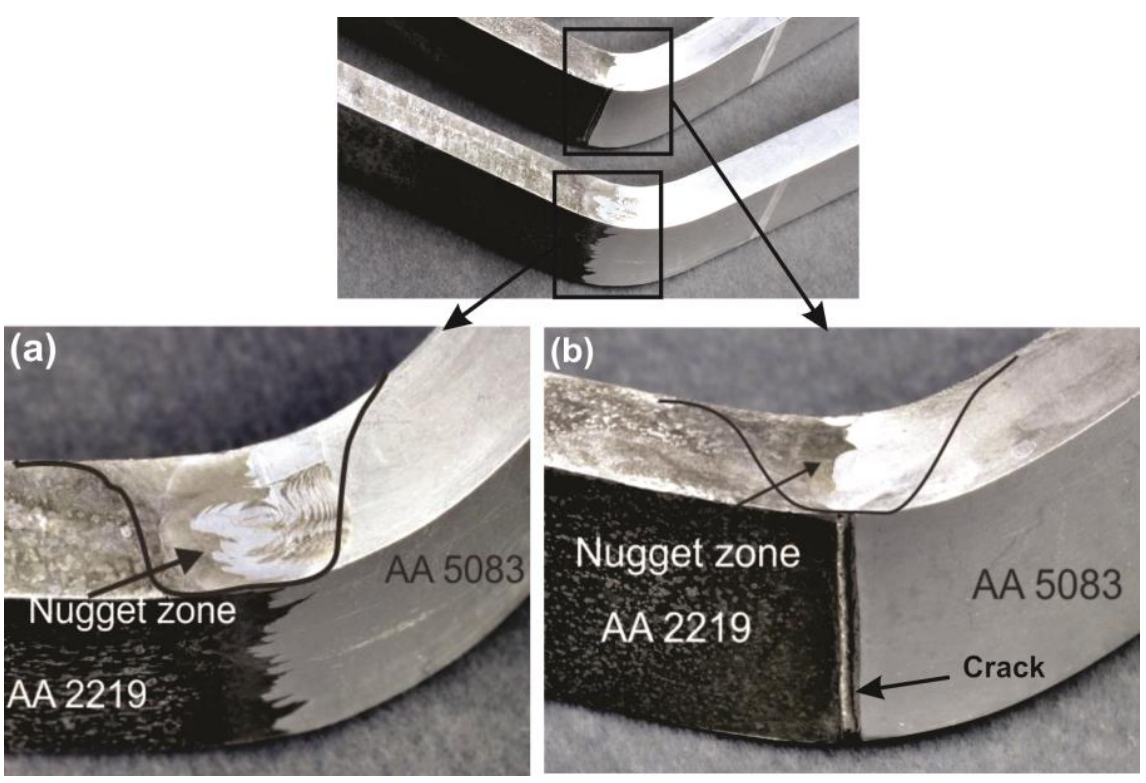

Fig. 19. The face bend test specimens of thoroughly and partially mixed dissimilar friction stir welds after bend testing

\section{Conclusions}

In the preset work the interaction effect of welding parameters and tool axis offset from joint interface, on the intermixing pattern, tensile properties of the friction stir weld joint of dissimilar 
aluminum alloys (AA2219 and AA5083) was studied. The following conclusions are drawn based on the results of the entire study.

1. Defect free welds can be obtained across a very wide range of conditions. But only those welds undertaken at the lowest rotation speed and highest traverse speed and tool offset towards AA2219 alloy side, resulted in defective welds. Established mathematical models presented a good prediction of relationship between the investigated FSW process parameters and the $\%$ area of defect of the welds, so that maximum error between the experimental data and predicted model values was less than $10 \%$.

2. The mixing pattern in nugget zone is predominantly affected by the tool offset and welding parameters. The extent of intermixing depends on the tool rotation speed and tool traverse speed. Intimate mixing of dissimilar alloys was observed at higher tool rotation speeds and lower tool traverse speeds.

3. The failure location of dissimilar friction stir weld is affected by the type of mixing pattern in the nugget zone. Poor mixing of materials in nugget zone leads to fracture of tensile specimens at nugget zone. It is possible to shift the failure location from nugget zone to HAZ of base materials by properly selecting welding parameters which favorable to intimate mixing in nugget zone.

4. The joint efficiencies of nearly $97 \%$ on UTS may be achieved in the dissimilar friction stir welds of AA2219 and AA5083 aluminum alloys.

The particular dissimilar joints friction stir welded under the conditions of high heat input (tool rotation speed varying from 400 to $2000 \mathrm{rpm}$ ) and lowest tool traverse speed of $30 \mathrm{~mm} / \mathrm{min}$ are found to be defect free and contained extensive intermixing in the nugget zone. These dissimilar joints possessed better tensile strength and percentage elongation.

\section{Acknowledgement}

The financial support from Defence Research and Development Organization is greatly acknowledged. The authors are thankful to Shri K.Jayaraman, Director, Defence Research and Development Laboratory (DRDL) and Dr.Amol. A. Gokhale, Director, Defence Metallurgical Research Laboratory (DMRL) for their continued encouragement and for according permission to publish this work.

\section{References}

1. Olson DL, Siewert TA, Liu S, Edwards GR. ASM Handbook Volume 6: Welding, Brazing, and Soldering, ASM International, 1993, ISBN: 978-0-87170-382-8.

2. Mishra RS, Ma ZY. Friction stir welding and processing, Materials Science and Engineering R, 2005; 50:1-78.

3. Threadgill PL, Leonard AJ, Shercliff HR, Withers PJ. Friction stir welding of aluminium alloys, International materials reviews, 2009; 54, No.2: 49-93. 
4. Heinz A, Haszler A, Keidel C, Moldenhauer S, Benedictus R, Miller WS. Recent development in aluminium alloys for aerospace applications, Materials Science and Engineering A, 2000; 280: 102-107.

5. JamshidiAval H, Kokabi AH, Serajzadeh S, Sakharova NA. A study on microstructures and residual stress distributions in dissimilar friction-stir welding of AA5086-AA6061, J Mater Sci., 2012; 47: 5428-5437.

6. Ghosh M, Kumar K, Kailas SV, Ray AK. Optimization of friction stir welding parameters for dissimilar aluminum alloys, Materials and Design, 2010; 31: 3033-3037.

7. Kumar K, Satish V Kailas. On the role of axial load and the effect of interface position on the tensile strength of a friction stir welded aluminum alloy, Materials\&Design,2008; 29: $791-797$.

8. Hidetoshi Fujii, Ling Cui, Masakatsu Maeda, Kiyoshi Nogi. Effect of tool shape on mechanical properties and microstructure of friction stir welded aluminum alloys, Materials Science and Engineering A,2006;419:25-31.

9. Elangovan K, Balasubramanian V. Influences of pin profile and rotational speed of the tool on the formation of friction stir processing zone in AA2219 aluminium alloy, Materials Science and Engineering A,2007;459:7-18.

10. Olivier Lorrain, Veronique Favier, Hamid Zahrouni, Didier Lawrjaniec. Understanding the material flow path of friction stir welding process using unthreaded tools, Journal of Material Processing Technology 2010; 210: 603-609.

11. DebRoy T, Bhadeshia HKDH. Friction stir welding of dissimilar alloys-a perspective, Science and technology of welding and joining, 2010; 15: 266 to 270.

12. Genevois C, Girard M, Huneau B, Sauvage X, Racineux G. Interfacial reaction during friction stir welding of $\mathrm{Al}$ and $\mathrm{Cu}$ ', Metallurgical and materials transactions $\mathrm{A}, 2011 ; 42$ : 2290 to 2295.

13. Xue P, Ni DR, Wang D, Xiao BL, Ma ZY. Effect of friction stir welding parameters on the microstructure and mechanical properties of the dissimilar Al-Cu joints, Materials Science and Engineering A, 2011; 528: 4683 - 4689.

14. Cavaliere P, Panella F. Effect of tool position on the fatigue properties of dissimilar 2024 -7075 sheets joined by friction stir welding, Journal of Materials Processing Technology, 2008; 206: 249-255.

15. Amancio-Filho ST, Sheikhi S, Dos Santos JF, Bolfarini C. Preliminary study on the microstructure and mechanical properties of dissimilar friction stir welds in aircraft aluminium alloys 2024-T351 and 6056-T4, Journal of Material Processing Technology 2008; 206: 132-142.

16. Park SK, Hong ST, Park JH, Park KY, Kwon YJ, Son HJ. Effect of material locations on properties of friction stir welding joints of dissimilar aluminum alloys, Science and technology of welding and joining,2010; 15, No.4: 331-336.

17. Dilip JJS, Koilraj M, Sundareswaran V, Janakiram GD, Koteswara Rao SR. Microstructural characterization of dissimilar friction stir welds between AA2219 and AA5083, Transactions of Indian Institute of Metals, 2012; 63, Issue 4: 757-764. 
18. Cho JR, Bae WB, Hwang WJ, Hartley P., A study on the hot deformation behavior and dynamic recrystallization of Al-5wt.\% Mg alloy, Journal of Materials Processing Technology, 2001; 118: 356-361.

19. Kaibyshev R, Sitdikov O, Mazurina I, Lesuer DR, Deformation behavior of a 2219 Al alloy, Materials Science and Engineering A, 2002; 334: 104-113.

20. Douglas C. Montgomery. Design and Analysis of Experiments, 5th Edition, John Wiley \& Sons, Inc., 2000, ISBN 13: 9780471316497.

21. FurkanSarsilmaz, UlasÇaydas. Statistical analysis on mechanical properties of frictionstir-welded AA 1050/AA 5083 couples, Int. J. Adv. Manuf. Technol., 2009; 43: 248-255.

22. PouyaBahemmat, Mohammad Haghpanahi, Mohammad KazemBesharatiGivi, KambizReshadSeighalani. Study on dissimilar friction stir butt welding of AA7075 -O and AA 2024-T4 considering manufacturing limitation', International Journal of advanced Manufacturing Technology, 2012; 59: 939 -953.

23. Palanivel R, Koshy Mathews P, Dinaharan I, Murugan N. Mechanical and metallurgical properties of dissimilar friction stir welded AA5083-H111 and AA6351-T6 aluminum alloys, Trans. Nonferrous Met. Soc. China, 2014; 24: 58-65.

24. Izadi H, Fallu J, Abdel-Gwad A, Liyanage T, Gerlich AP. Analysis of tool geometry in dissimilar Al alloy friction stir welds using optical microscopy and serial sectioning', Science and technology of welding and joining, 2013; 18, No.4: 307-313.

25. Ouyang JH, Kovacevic R. Material flow and microstructure in the friction stir butt welds of the same and dissimilar aluminium alloys, Journal of Materials Engineering and Performance, 2002; 11: 51-63. 